\title{
Intrinsic Branching Effects in Syndiotactic Copolymers of Propylene and Higher $\alpha$-Olefins
}

Eric D. Schwerdtfeger and Stephen A. Miller*

Department of Chemistry, Texas A\&M University

College Station, Texas 77843-3255

\section{Supporting Information}

Supporting Information Available: Additional polymer characterization data, representative NMR spectra, DSC thermograms, and a detailed analysis of monomer sequences.

\section{Table of Contents}

Polymer Pentad Distributions.

${ }^{13} \mathrm{C}$ NMR Spectra

DSC Thermograms

Analysis of Monomer Sequence Distributions

References
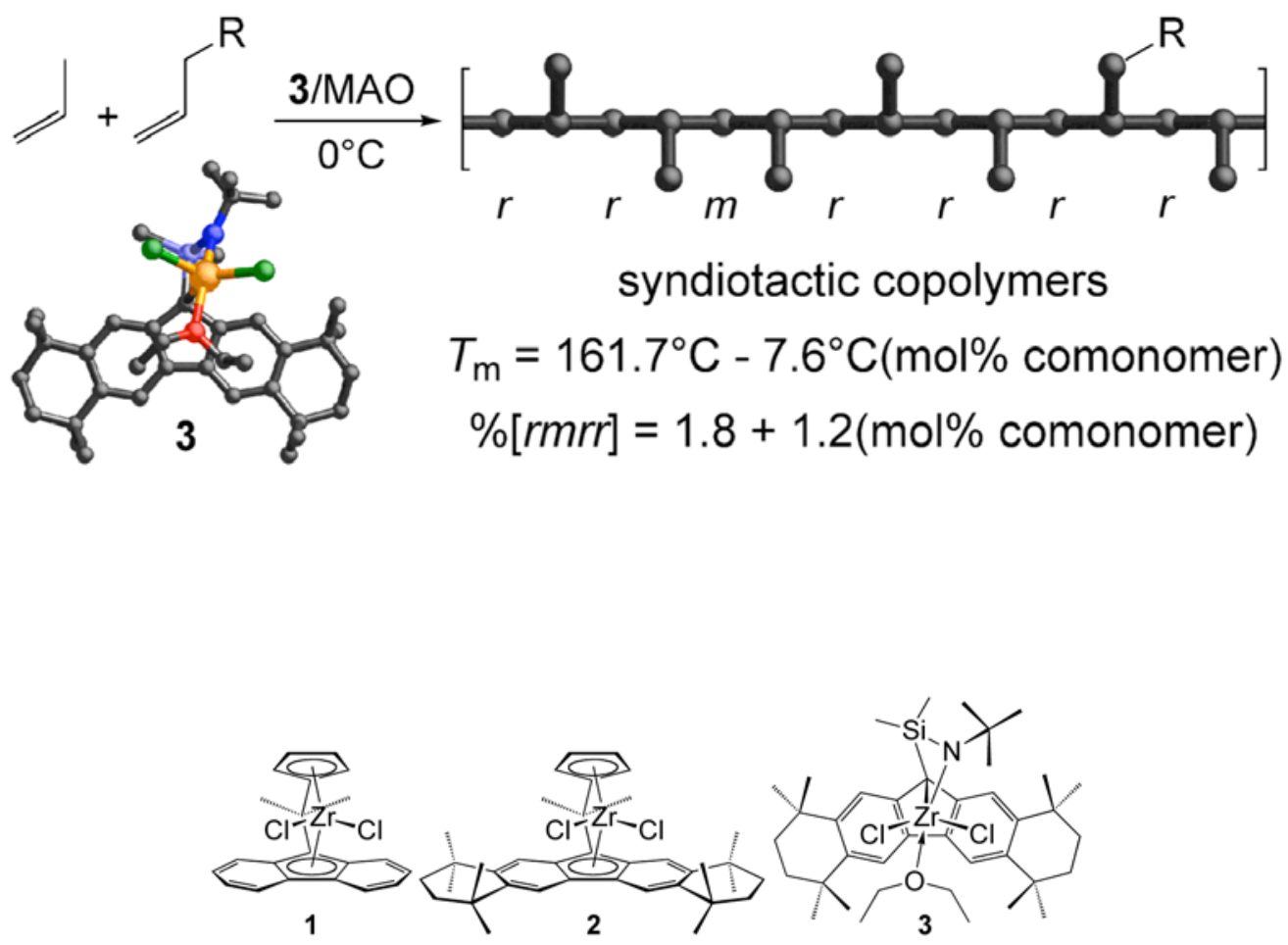
Table 1. Propylene/comonomer copolymerization results with $\mathbf{1 , 2}$, and $\mathbf{3}$ (activated with MAO). ${ }^{\mathrm{a}}$ entry ref. comon. comon. time yield $\mathrm{mmmm} \quad \mathrm{mmmr} \quad \mathrm{rmmr} \quad \mathrm{mmrr} \quad \mathrm{mrmm} \quad \mathrm{mrmr} \quad \mathrm{rrrr} \quad \mathrm{rrrm} \quad \mathrm{mrrm}$ incorp. $\quad(\min ) \quad(g)$

(\%)

\begin{tabular}{|c|c|c|c|c|c|c|c|c|c|c|c|c|c|c|}
\hline \multicolumn{15}{|c|}{$1 / \mathrm{MAO}$} \\
\hline 1 & ref. 1 & none & ---- & 5 & 0.32 & - & - & 1.0 & 2.5 & 1.0 & - & 91.4 & 4.1 & - \\
\hline 2 & $124-3$ & $4 \mathrm{Me1P}$ & 1.1 & 10 & 0.53 & - & - & 1.2 & 2.3 & 3.6 & - & 87.1 & 5.9 & - \\
\hline 3 & $70-3$ & $4 \mathrm{Me1P}$ & 3.0 & 3 & 0.33 & - & - & 1.1 & 2.1 & 6.8 & - & 81.2 & 8.9 & - \\
\hline 4 & $70-4$ & $4 \mathrm{Me1P}$ & 8.5 & 4 & 0.72 & - & - & 1.0 & 2.0 & 11.4 & - & 72.2 & 13.4 & - \\
\hline 5 & $70-5$ & $4 \mathrm{Me1P}$ & 8.0 & 2 & 0.30 & - & - & 0.6 & 1.2 & 11.3 & - & 74.3 & 12.5 & - \\
\hline 6 & $70-13$ & 4Me1P & 17.8 & 2 & 0.39 & - & - & 0.8 & 1.6 & 23.8 & - & 48.2 & 25.5 & - \\
\hline 7 & $70-6$ & hexene & 0.8 & 2 & 0.18 & - & - & 1.1 & 2.3 & 3.4 & - & 87.5 & 5.7 & - \\
\hline 8 & $70-7$ & hexene & 5.0 & 2 & 0.23 & - & - & 0.9 & 1.9 & 10.7 & - & 74.0 & 12.5 & - \\
\hline 9 & $70-8$ & hexene & 8.9 & 2 & 0.32 & - & - & 0.9 & 1.8 & 15.5 & - & 64.6 & 17.3 & - \\
\hline 10 & $70-9$ & hexene & 19.8 & 2 & 0.42 & - & - & 1.5 & 2.9 & 27.6 & - & 37.3 & 30.6 & - \\
\hline 11 & $70-10$ & octene & 1.7 & 2 & 0.26 & - & - & 0.8 & 1.6 & 2.3 & - & 91.2 & 4.0 & - \\
\hline 12 & $91-1$ & octene & 1.4 & 2 & 0.07 & - & - & 0.7 & 1.5 & 2.7 & - & 91.0 & 4.1 & - \\
\hline 13 & $70-11$ & octene & 4.6 & 2 & 0.49 & - & - & 0.6 & 1.2 & 8.7 & - & 79.7 & 9.9 & - \\
\hline 14 & $70-12$ & octene & 10.0 & 2 & 0.31 & - & - & 0.8 & 1.6 & 13.0 & - & 69.9 & 14.6 & - \\
\hline 15 & $91-2$ & octene & 12.1 & 2 & 0.05 & - & - & 2.2 & 4.3 & 26.0 & - & 37.2 & 30.3 & - \\
\hline 16 & $91-3$ & decene & 1.2 & 2 & 0.05 & - & - & 1.6 & 3.3 & 3.4 & - & 84.9 & 6.7 & - \\
\hline 17 & $91-4$ & decene & 4.3 & 2 & 0.14 & - & - & 0.7 & 1.4 & 7.1 & - & 82.4 & 8.5 & - \\
\hline 18 & $91-6$ & decene & 9.3 & 2 & 0.31 & - & - & 1.4 & 2.7 & 13.1 & - & 67.1 & 15.8 & - \\
\hline \multicolumn{15}{|c|}{ 2/MAO } \\
\hline 19 & ref. 1 & none & ---- & 5 & 0.23 & - & - & - & - & 1.6 & - & 95.6 & 2.8 & - \\
\hline 20 & 73-1 & $4 \mathrm{Me} 1 \mathrm{P}$ & 1.0 & 2 & 0.13 & - & - & 0.2 & 0.3 & 1.7 & - & 95.7 & 2.1 & - \\
\hline 21 & $73-3$ & $4 \mathrm{Me} 1 \mathrm{P}$ & 2.7 & 2 & 0.09 & - & - & 0.5 & 0.9 & 6.1 & - & 85.6 & 7.0 & - \\
\hline 22 & 73-4 & $4 \mathrm{Me} 1 \mathrm{P}$ & 4.4 & 2 & 0.08 & - & - & 0.1 & 0.3 & 8.1 & - & 83.1 & 8.4 & - \\
\hline 23 & $73-5$ & $4 \mathrm{Me} 1 \mathrm{P}$ & 10.1 & 2 & 0.01 & - & - & 0.1 & 0.3 & 11.4 & - & 76.5 & 11.7 & - \\
\hline 24 & $73-6$ & hexene & 2.0 & 2 & 0.21 & - & - & 0.4 & 0.8 & 2.9 & - & 92.2 & 3.7 & - \\
\hline 25 & 73-7 & hexene & 4.1 & 2 & 0.40 & - & - & 0.6 & 1.2 & 7.1 & - & 82.8 & 8.3 & - \\
\hline 26 & $73-8$ & hexene & 5.8 & 2 & 0.25 & - & - & 0.1 & 0.2 & 14.6 & - & 70.5 & 14.7 & - \\
\hline 27 & $73-9$ & hexene & 14.1 & 2 & 0.12 & - & - & 1.2 & 2.4 & 22.0 & - & 49.9 & 24.4 & - \\
\hline 28 & $73-10$ & octene & 0.9 & 2 & 0.16 & - & - & 0.2 & 0.4 & 3.6 & - & 91.9 & 4.0 & - \\
\hline 29 & $94-4$ & octene & 1.4 & 2 & 0.10 & - & - & 0.7 & 1.5 & 7.3 & - & 81.7 & 8.8 & - \\
\hline 30 & $73-11$ & octene & 3.1 & 2 & 0.22 & - & - & 0.4 & 0.8 & 6.1 & - & 85.8 & 6.9 & - \\
\hline 31 & $94-5$ & octene & 7.4 & 2 & 0.14 & - & - & 0.5 & 1.0 & 11.4 & - & 74.6 & 12.4 & - \\
\hline 32 & $94-6$ & octene & 15.1 & 2 & 0.16 & - & - & 1.0 & 2.0 & 20.8 & - & 53.4 & 22.8 & - \\
\hline 33 & $94-1$ & decene & 0.9 & 2 & 0.09 & - & - & 0.2 & 0.5 & 2.7 & - & 93.5 & 3.1 & - \\
\hline 34 & $94-2$ & decene & 3.7 & 2 & 0.13 & - & - & 0.2 & 0.3 & 6.3 & - & 86.5 & 6.7 & - \\
\hline 35 & $94-3$ & decene & 6.7 & 2 & 0.13 & - & - & 0.6 & 1.1 & 11.6 & - & 74.0 & 12.7 & - \\
\hline \multicolumn{15}{|c|}{ 3/MAO } \\
\hline 36 & ref. 1 & none & ---- & 5 & 0.54 & - & - & - & - & 1.1 & - & 97.6 & 1.3 & - \\
\hline 37 & $66-2$ & 4Me1P & 1.3 & 5 & 0.69 & - & - & 0.3 & 0.6 & 2.1 & - & 94.4 & 2.7 & - \\
\hline 38 & $66-3$ & 4Me1P & 2.8 & 5 & 0.77 & - & - & 0.2 & 0.5 & 4.3 & - & 90.2 & 4.8 & - \\
\hline 39 & 66-4 & $4 \mathrm{Me} 1 \mathrm{P}$ & 3.7 & 2 & 0.08 & - & - & 0.2 & 0.5 & 5.1 & - & 88.7 & 5.5 & - \\
\hline 40 & 84-1 & $4 \mathrm{Me} 1 \mathrm{P}$ & 6.5 & 2 & 0.15 & - & - & 0.4 & 0.8 & 10.3 & - & 77.4 & 11.1 & - \\
\hline 41 & $84-2$ & 4Me1P & 15.8 & 2.5 & 0.14 & - & - & 0.8 & 1.6 & 15.6 & - & 64.7 & 17.3 & - \\
\hline 42 & $84-4$ & hexene & 2.5 & 2 & 0.02 & - & - & 0.3 & 0.6 & 3.8 & - & 90.9 & 4.4 & - \\
\hline 43 & $84-5$ & hexene & 4.8 & 2 & 0.10 & - & - & 0.2 & 0.5 & 7.7 & - & 83.4 & 8.2 & - \\
\hline 44 & $84-6$ & hexene & 8.6 & 2 & 0.10 & - & - & 0.5 & 1.1 & 14.6 & - & 68.0 & 15.7 & - \\
\hline 45 & 84-12 & hexene & 8.6 & 2 & 0.03 & - & - & 0.1 & 0.2 & 16.4 & - & 66.6 & 16.6 & - \\
\hline 46 & $84-7$ & hexene & 20.9 & 2 & 0.14 & - & - & 1.2 & 2.4 & 28.5 & - & 37.0 & 30.9 & - \\
\hline 47 & $84-8$ & octene & 1.0 & 2 & 0.21 & - & - & 0.2 & 0.3 & 2.8 & - & 93.7 & 3.1 & - \\
\hline 48 & $84-9$ & octene & 4.3 & 2 & 0.22 & - & - & 0.2 & 0.5 & 8.9 & - & 81.1 & 9.4 & - \\
\hline 49 & $84-10$ & octene & 7.4 & 2 & 0.11 & - & - & 0.5 & 0.9 & 12.5 & - & 72.6 & 13.5 & - \\
\hline 50 & $84-11$ & octene & 17.1 & 2 & 0.17 & - & - & 1.3 & 2.5 & 22.7 & - & 48.4 & 25.2 & - \\
\hline 51 & $93-1$ & decene & 1.2 & 2 & 0.24 & - & - & 0.2 & 0.5 & 1.9 & - & 95.1 & 2.3 & - \\
\hline 52 & $93-2$ & decene & 4.1 & 2 & 0.32 & - & - & 0.3 & 0.6 & 7.7 & - & 83.1 & 8.3 & - \\
\hline 53 & $93-3$ & decene & 5.6 & 2 & 0.26 & - & - & 0.4 & 0.9 & 9.8 & - & 78.2 & 10.7 & - \\
\hline
\end{tabular}

${ }^{\mathrm{a}}$ Data for entries 1, 19, and 36 are taken from reference 1. 
${ }^{13}$ C NMR Spectra

Copoly(propylene/4-methyl-1-pentene) ( $8.5 \mathrm{~mol} \%$ ) produced with 1/MAO (Table 1, entry 4)

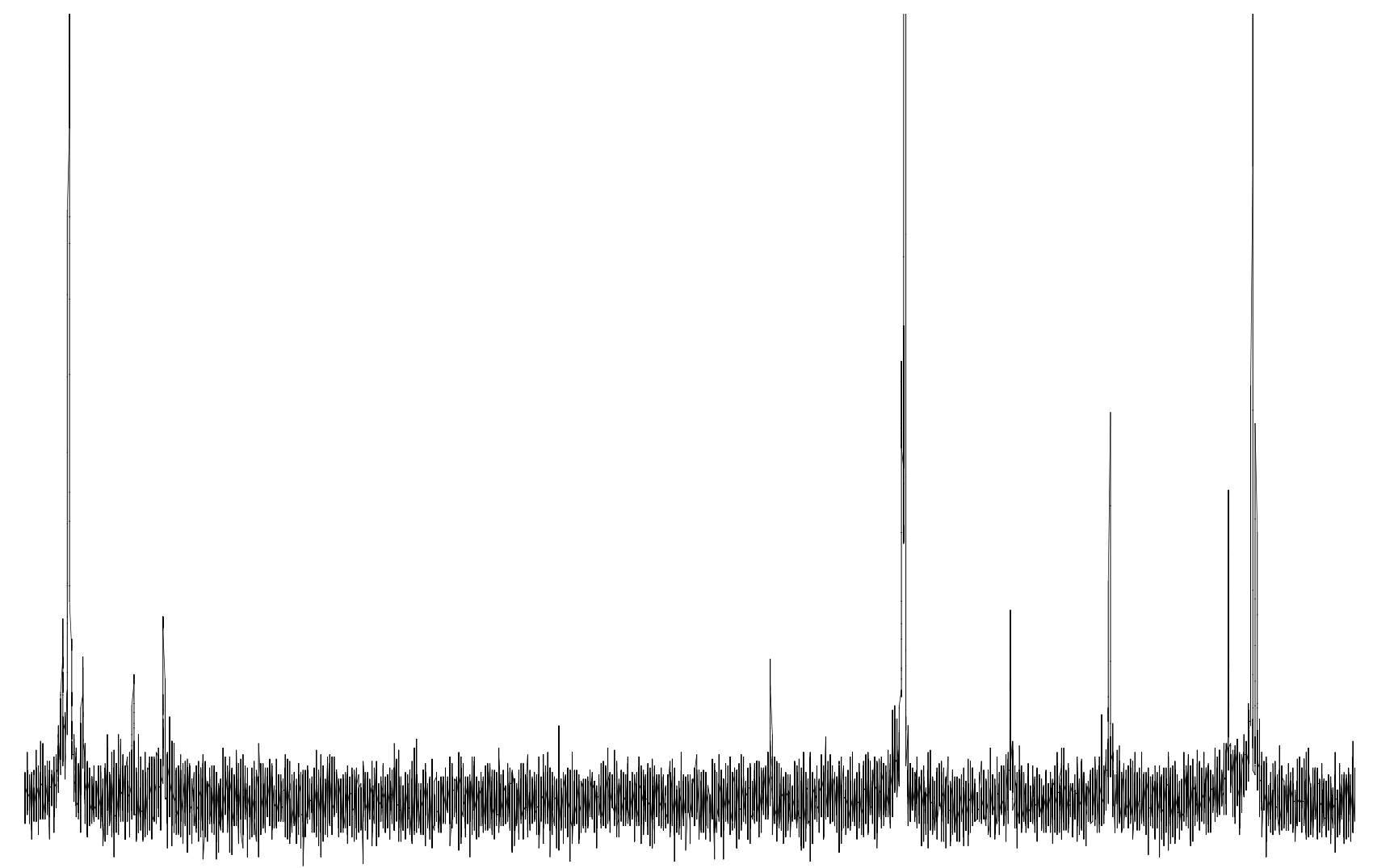

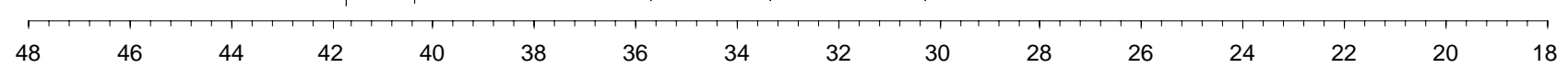

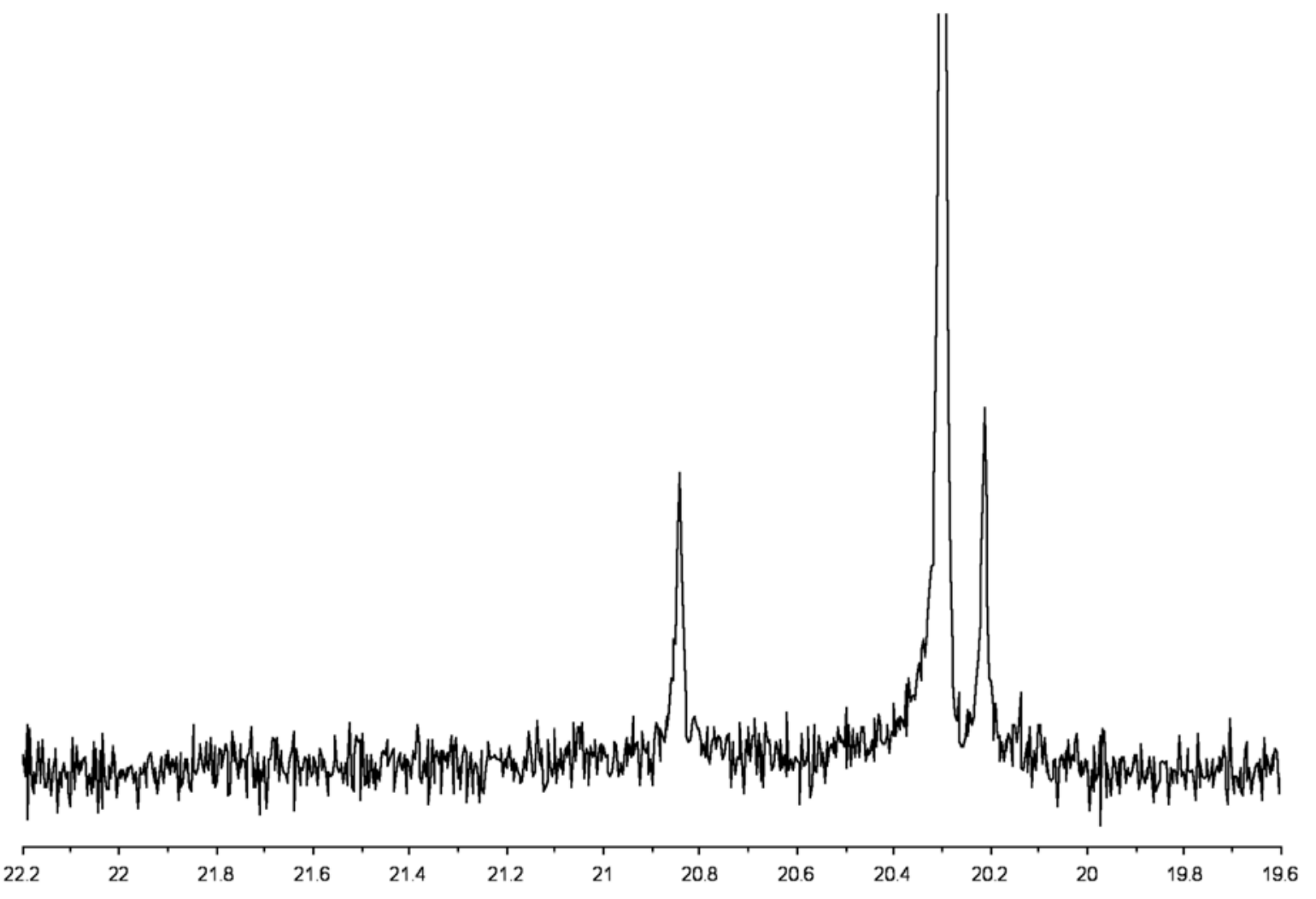

SB 
Copoly(propylene/1-hexene) (5.0 mol \%) produced with 1/MAO (Table 1, entry 8)
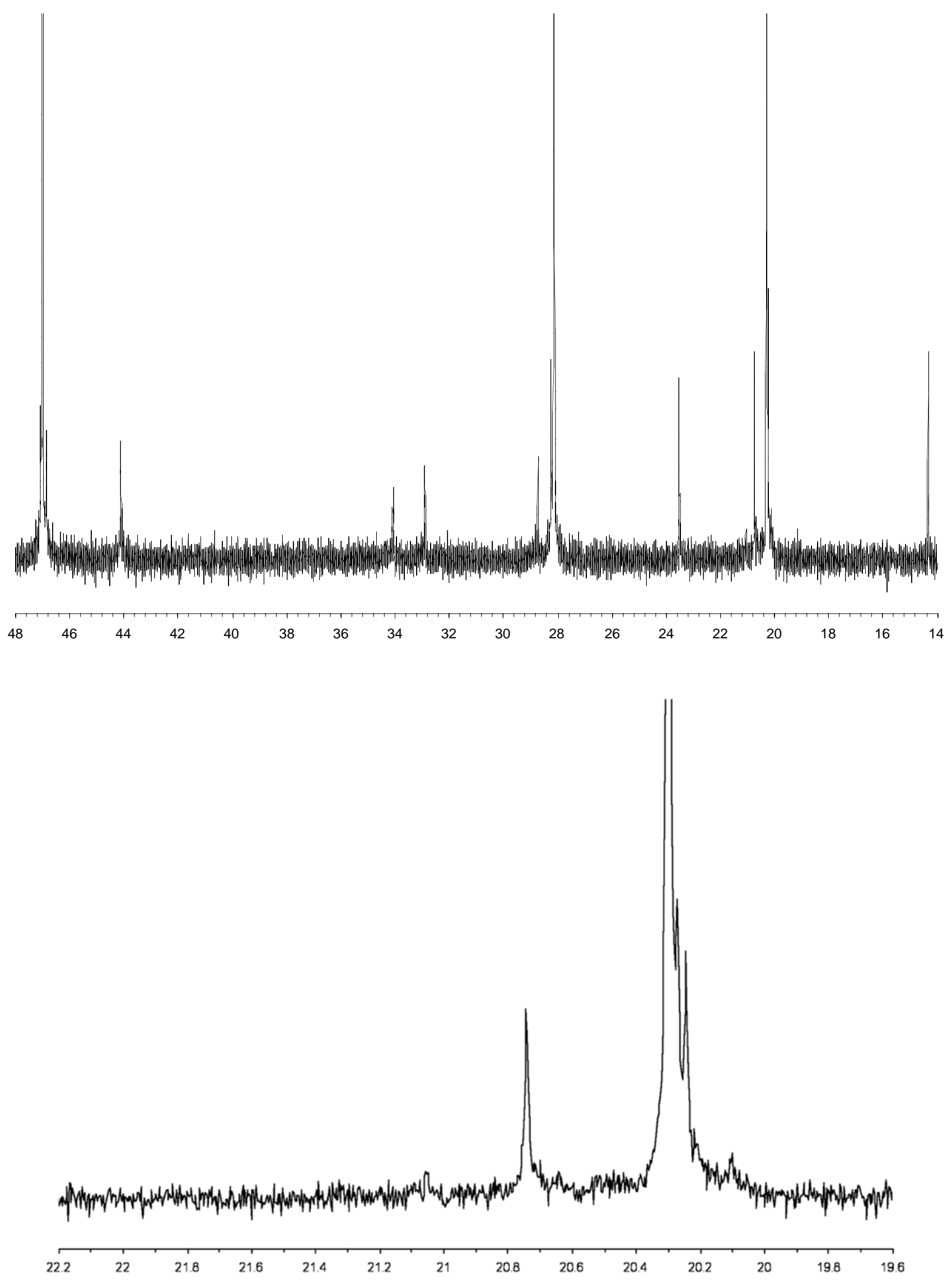
Copoly(propylene/1-octene) (4.6 mol \%) produced with 1/MAO (Table 1 , entry 13 )
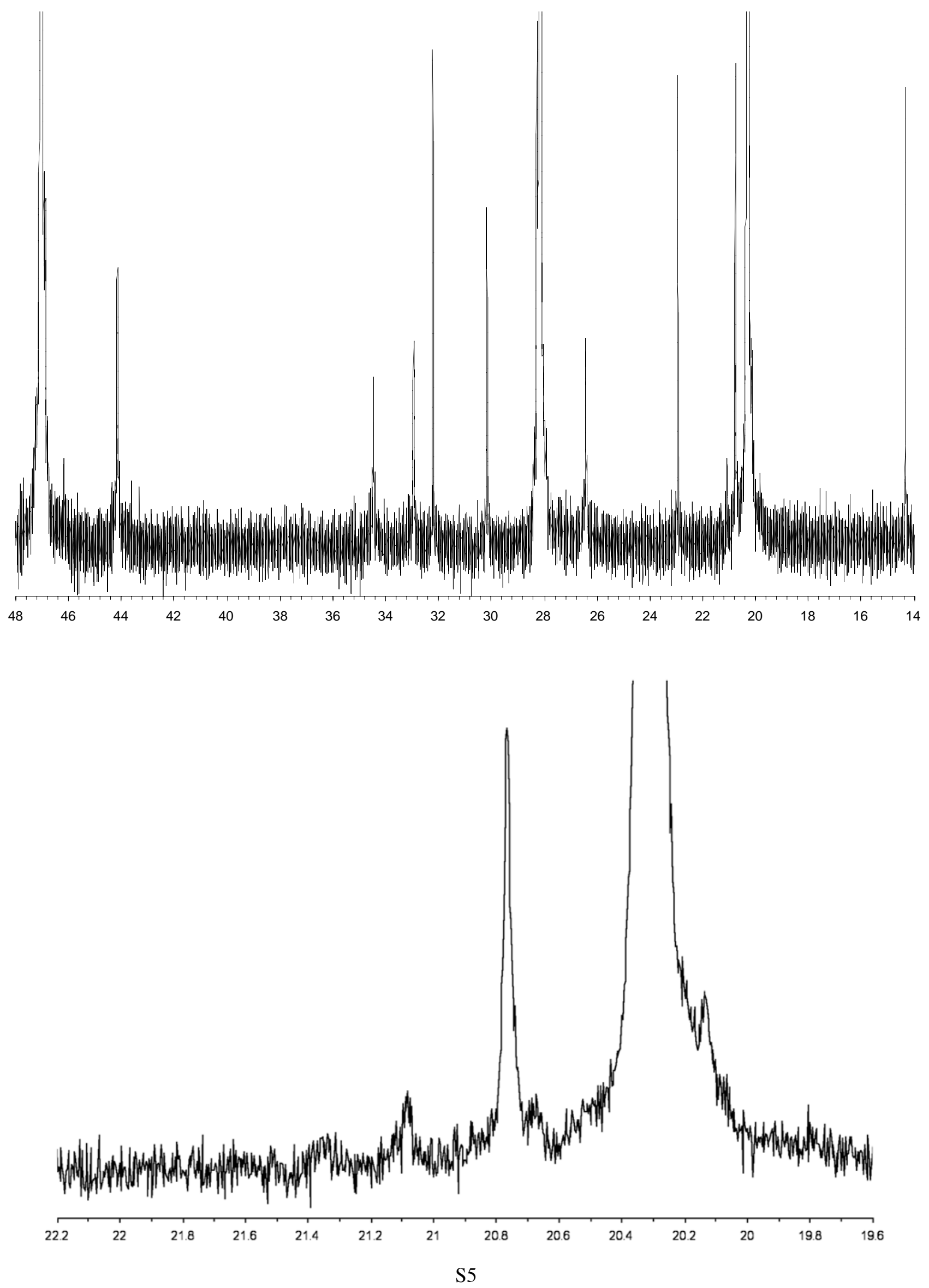
Copoly(propylene/1-decene) (4.3 mol \%) produced with 1/MAO (Table 1, entry 17)
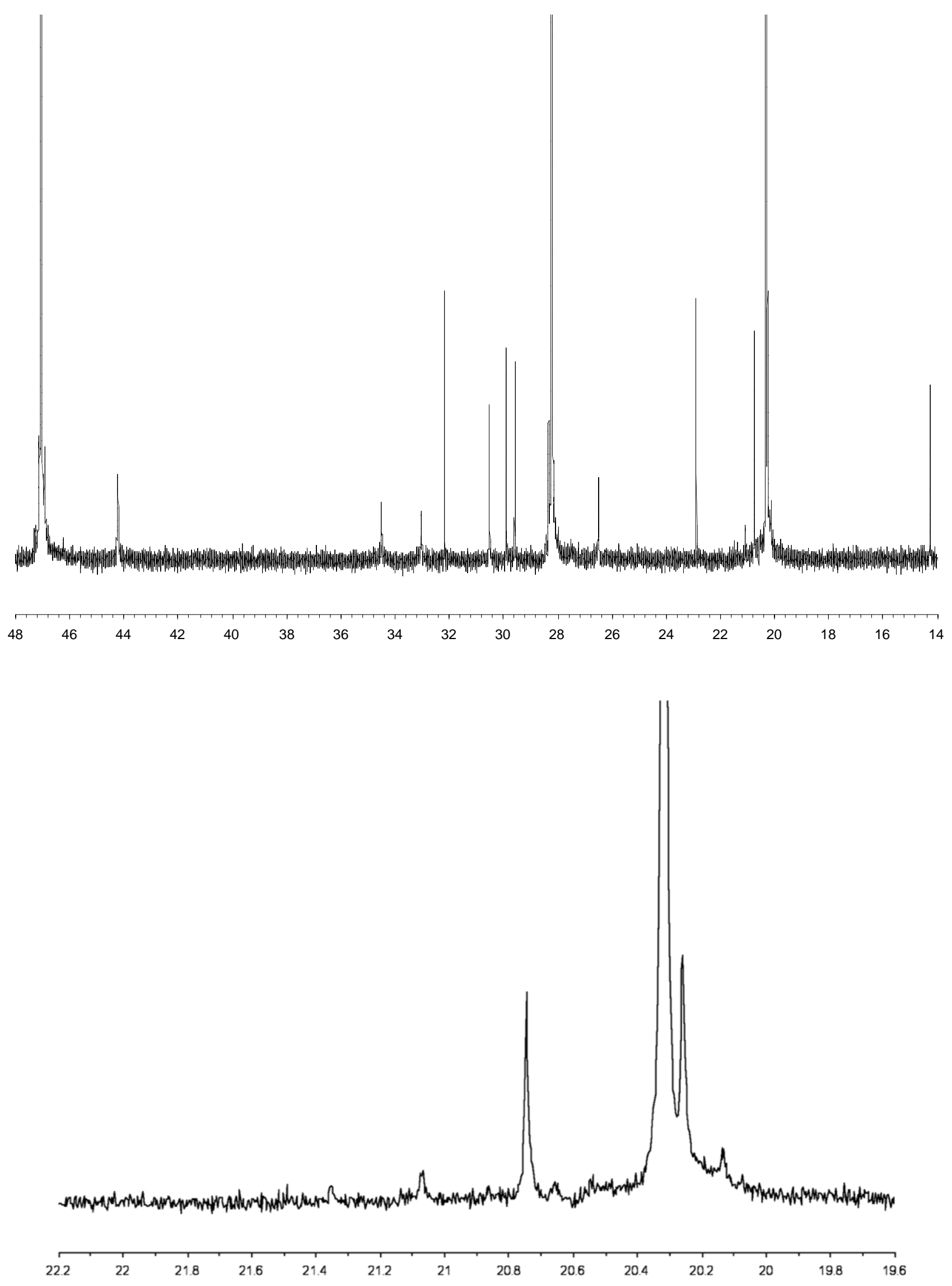
Copoly(propylene/4-methyl-1-pentene) (2.7 mol \%) produced with 2/MAO (Table 1, entry 21)
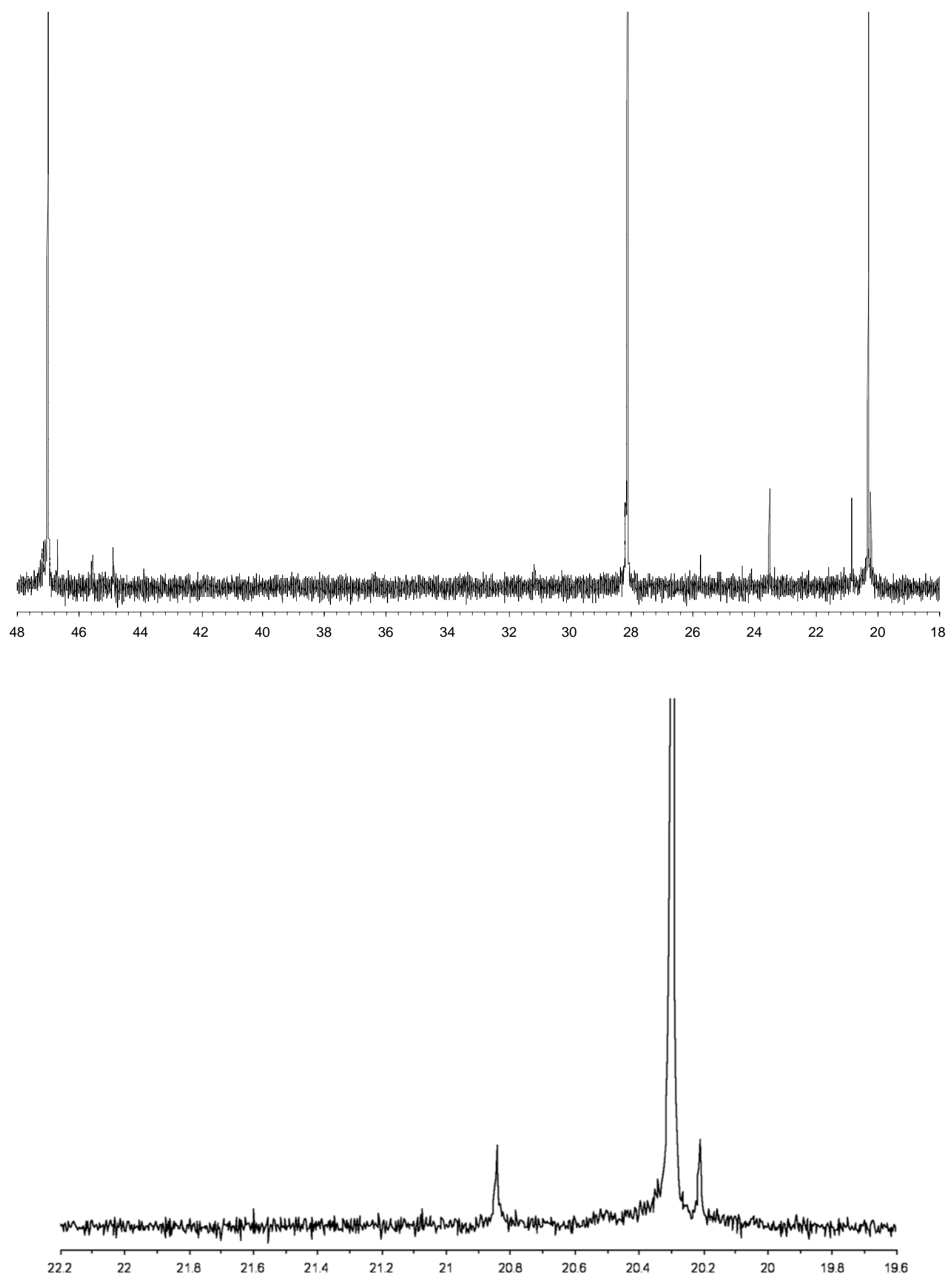
Copoly(propylene/1-hexene) (14.1 mol \%) produced with 2/MAO (Table 1, entry 27)
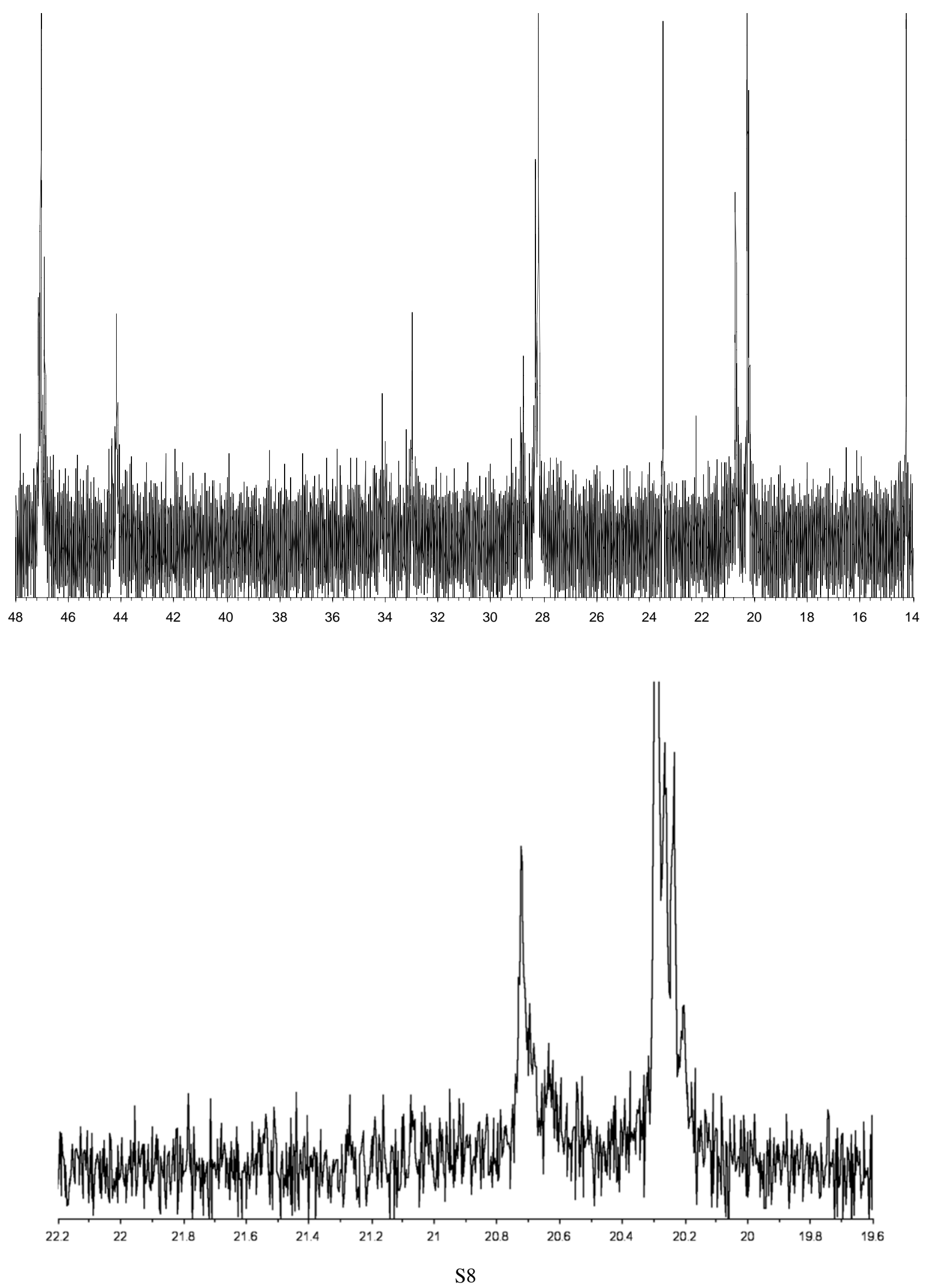
Copoly(propylene/1-octene) ( 7.4 mol \%) produced with 2/MAO (Table 1, entry 31 )
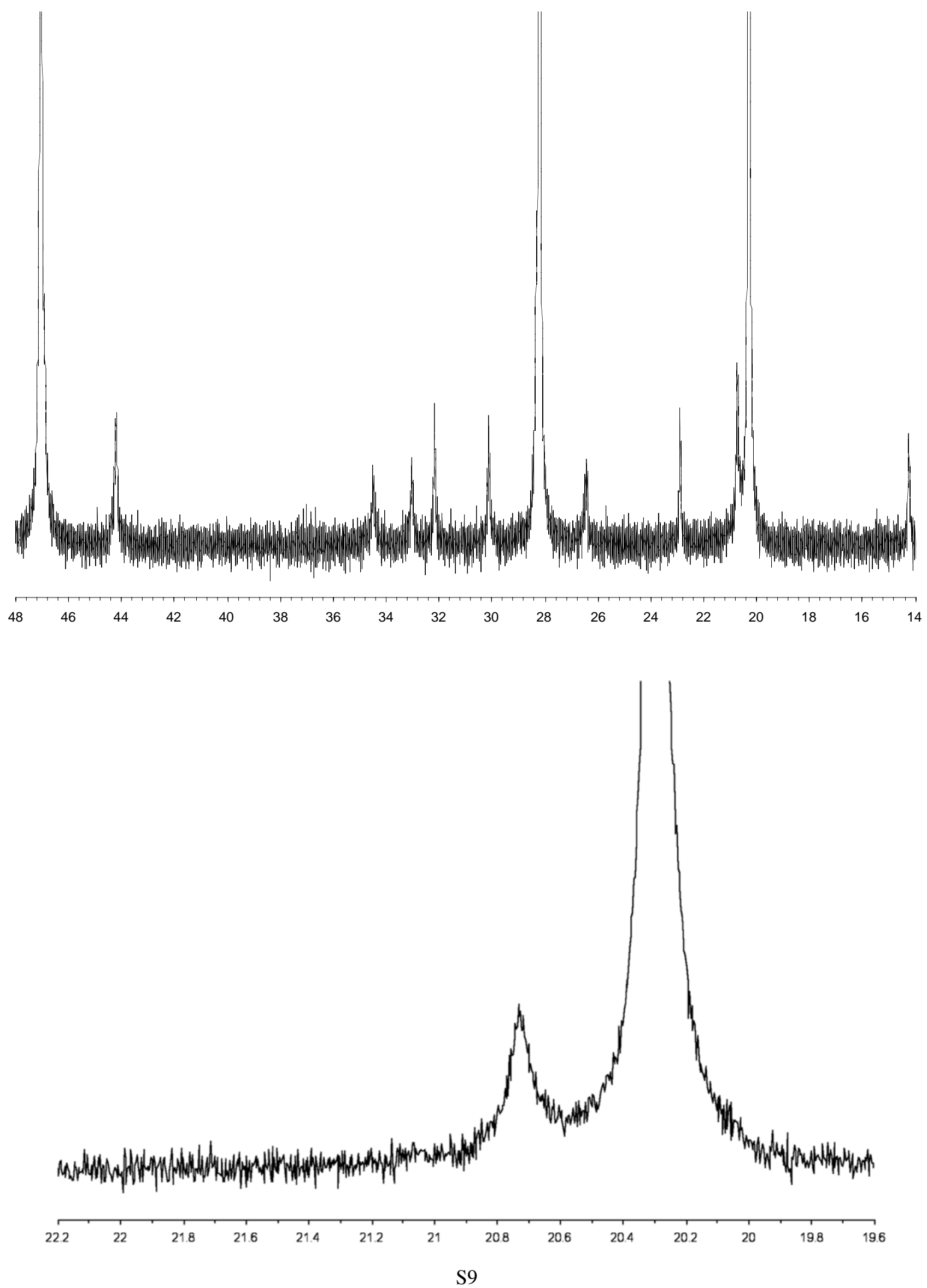
Copoly(propylene/1-decene) (3.7 mol \%) produced with 2/MAO (Table 1, entry 34)
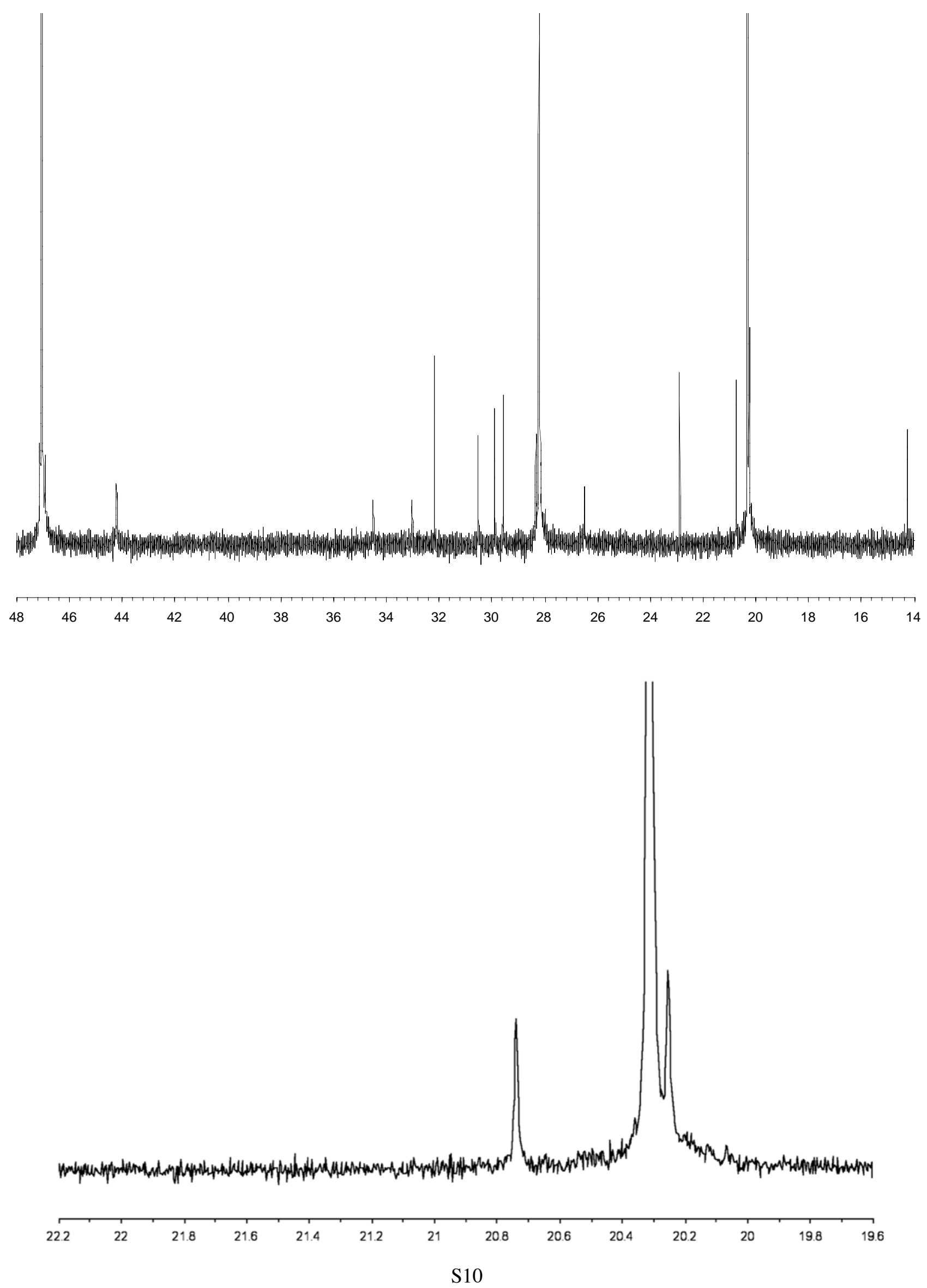
Copoly(propylene/4-methyl-1-pentene) (2.8 mol \%) produced with 3/MAO (Table 1, entry 38)
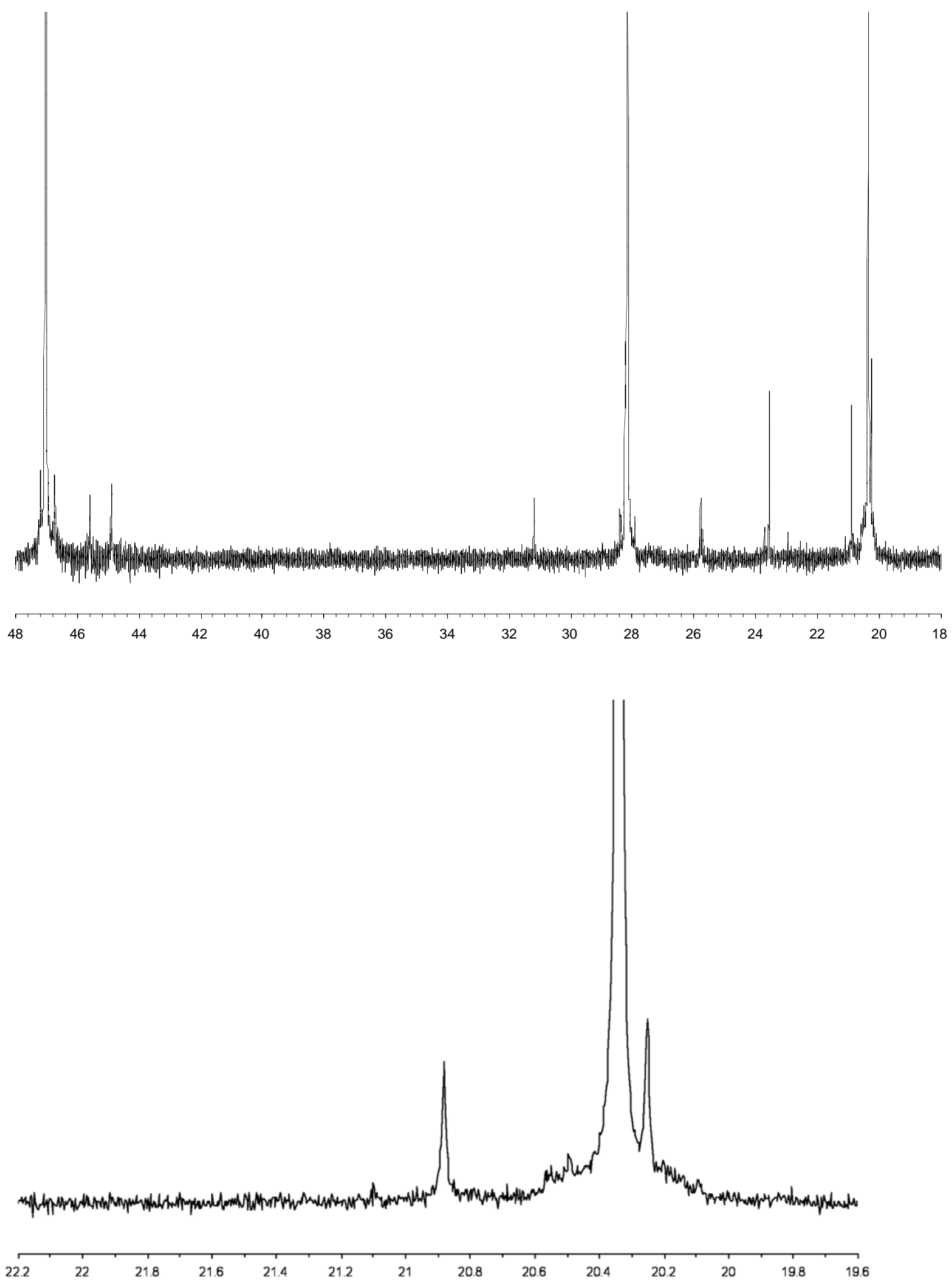


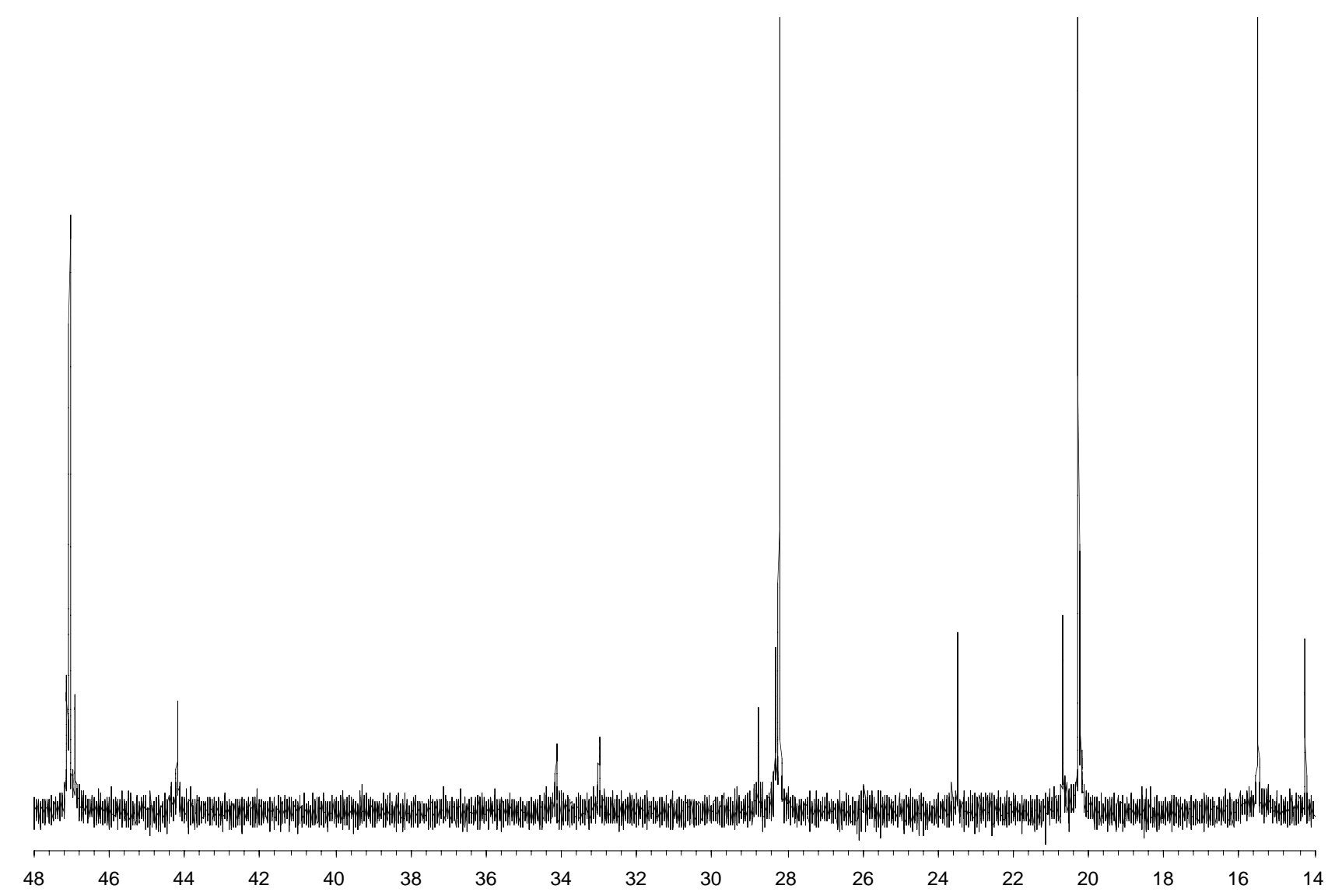

The peak at $15.5 \mathrm{ppm}$ (and another at $65.8 \mathrm{ppm}$ ) indicates the inadvertent presence of diethyl ether.

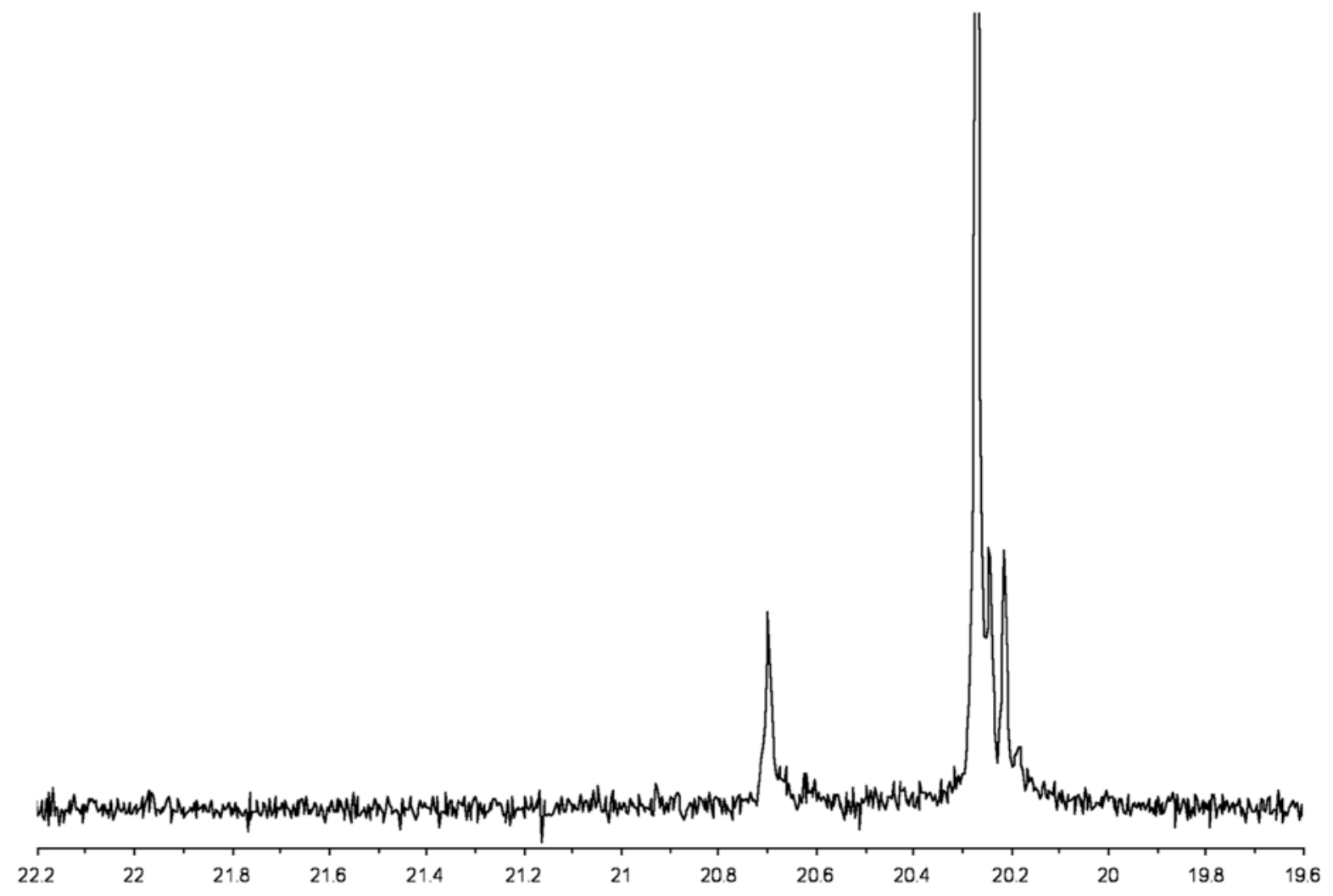


Copoly(propylene/1-octene) (4.3 mol \%) produced with 3/MAO (Table 1 , entry 48 )
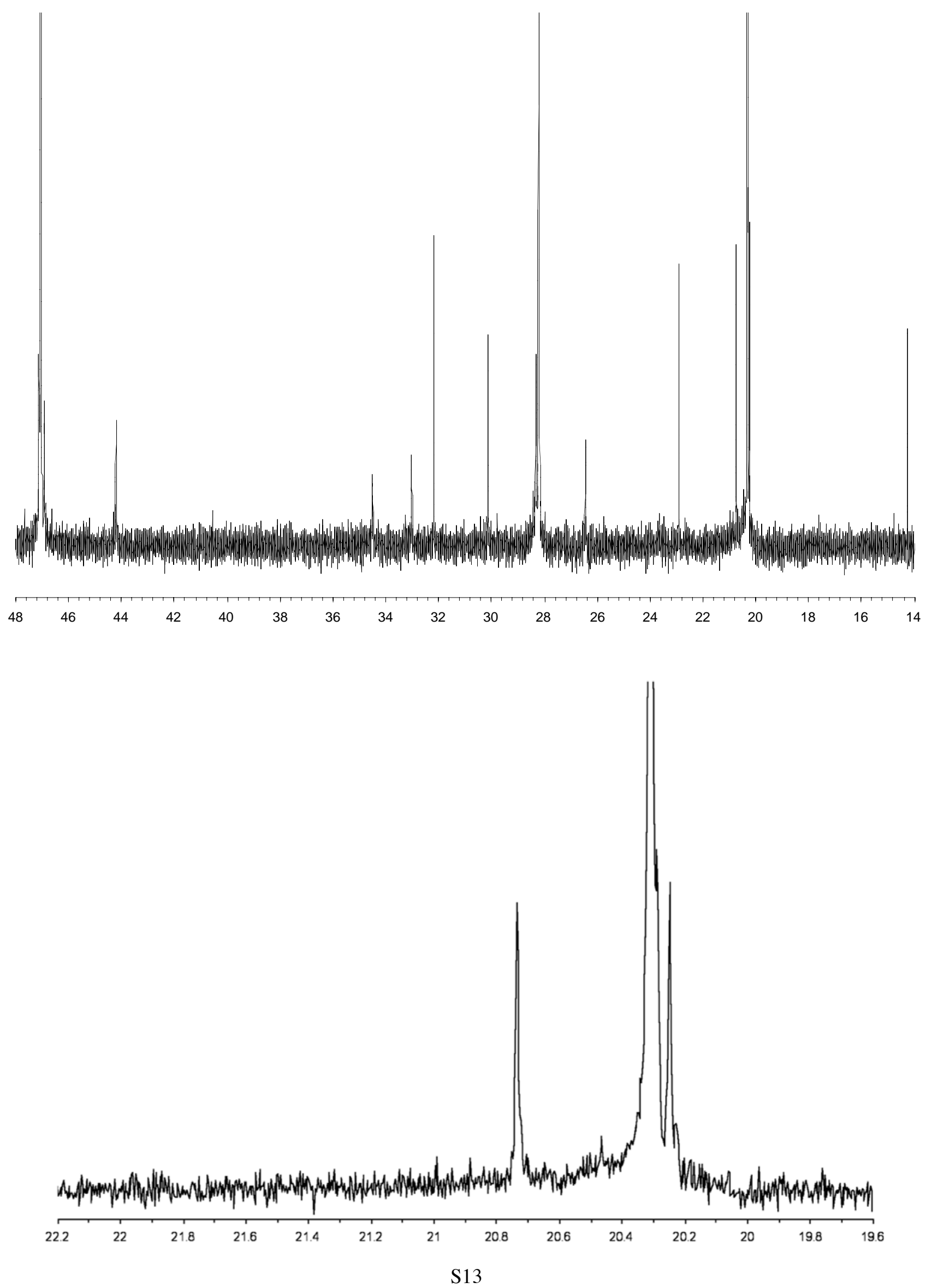
Copoly(propylene/1-decene) (4.1 mol \%) produced with 3/MAO (Table 1, entry 52)
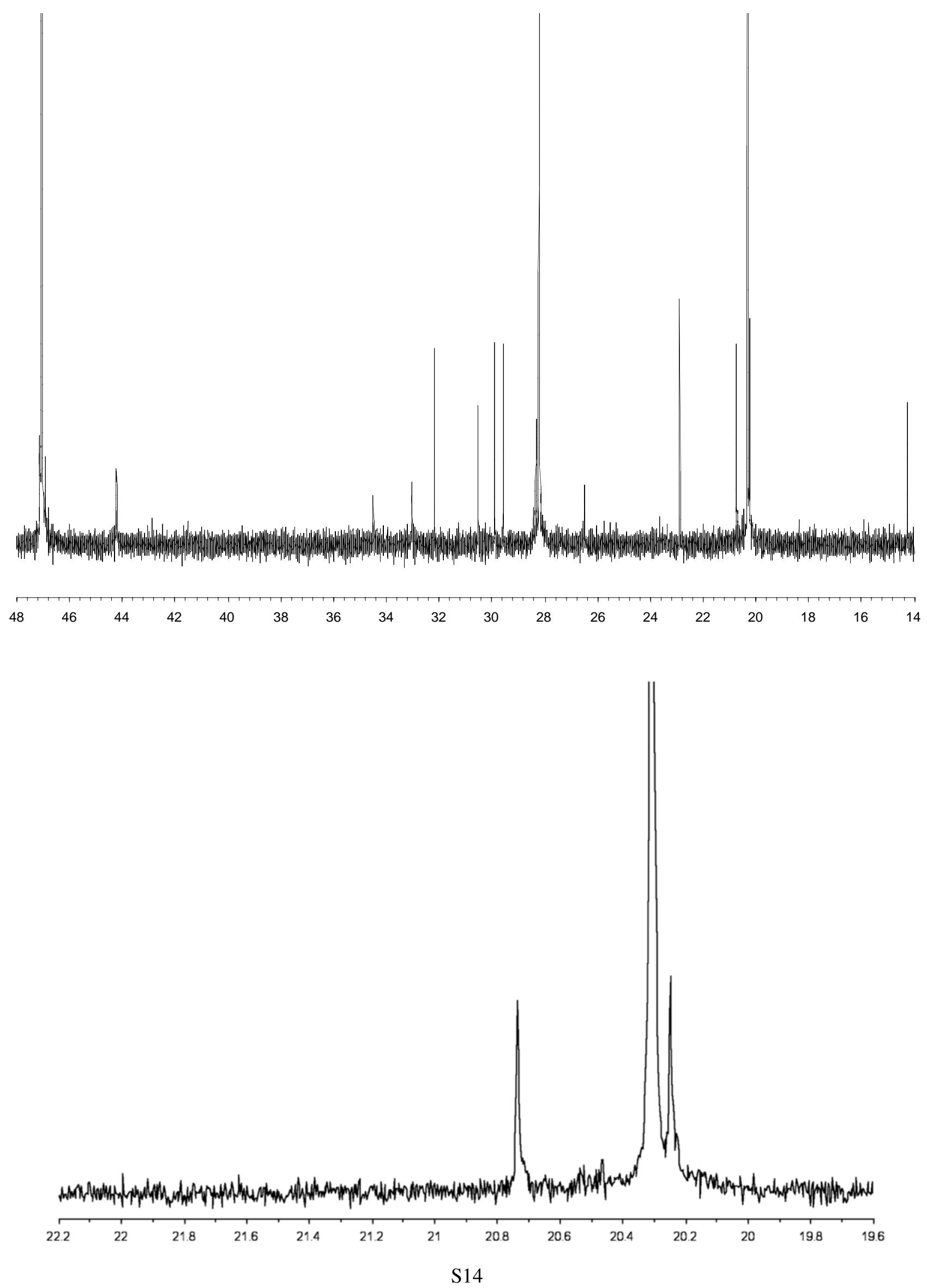


\section{DSC Thermograms}

Copoly(propylene/4-methyl-1-pentene) (1.1 mol \%) produced with 1/MAO (Table 1, entry 2)

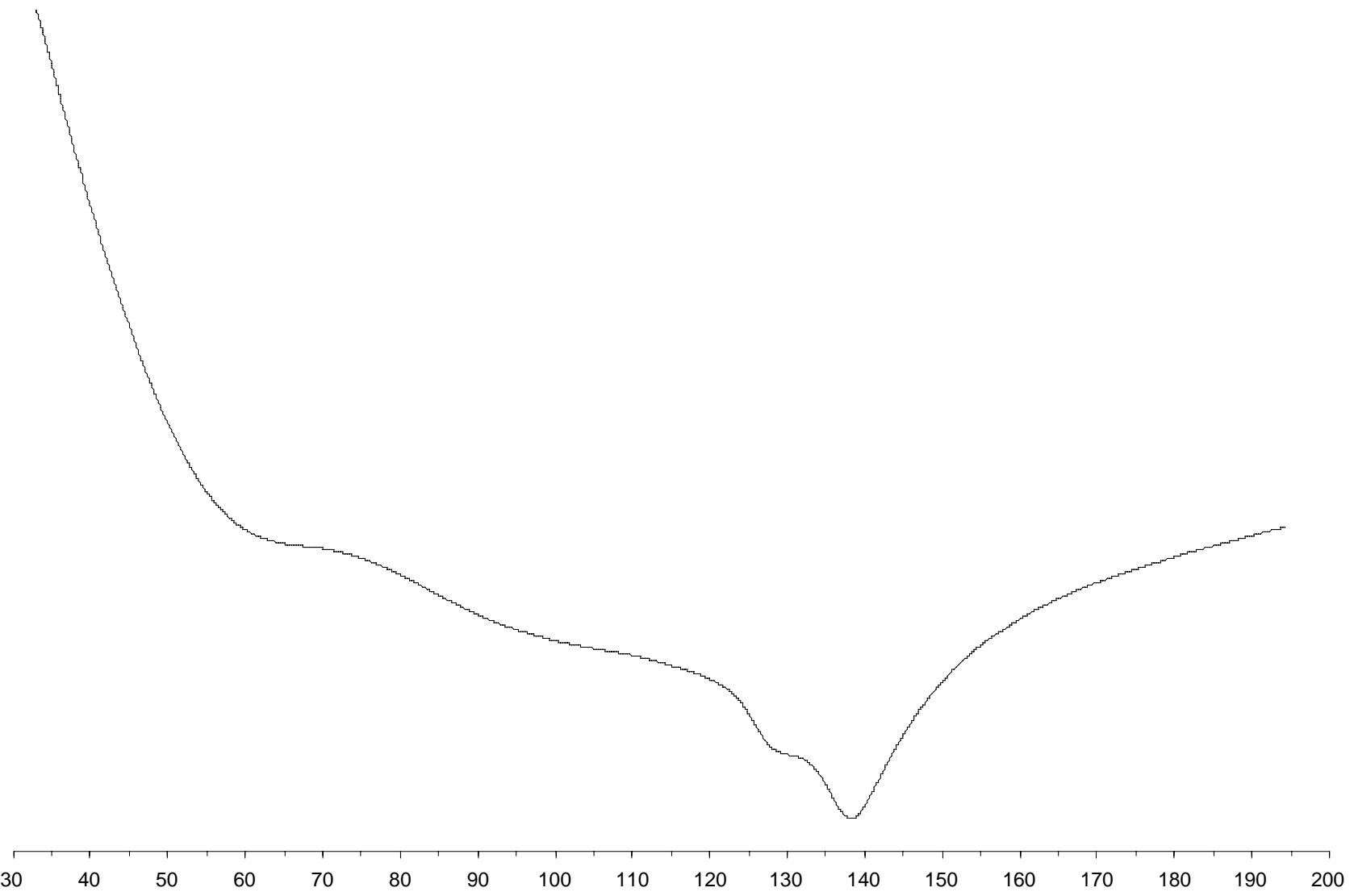


Copoly(propylene/1-hexene) $(0.8 \mathrm{~mol} \%)$ produced with 1/MAO (Table 1 , entry 7 )

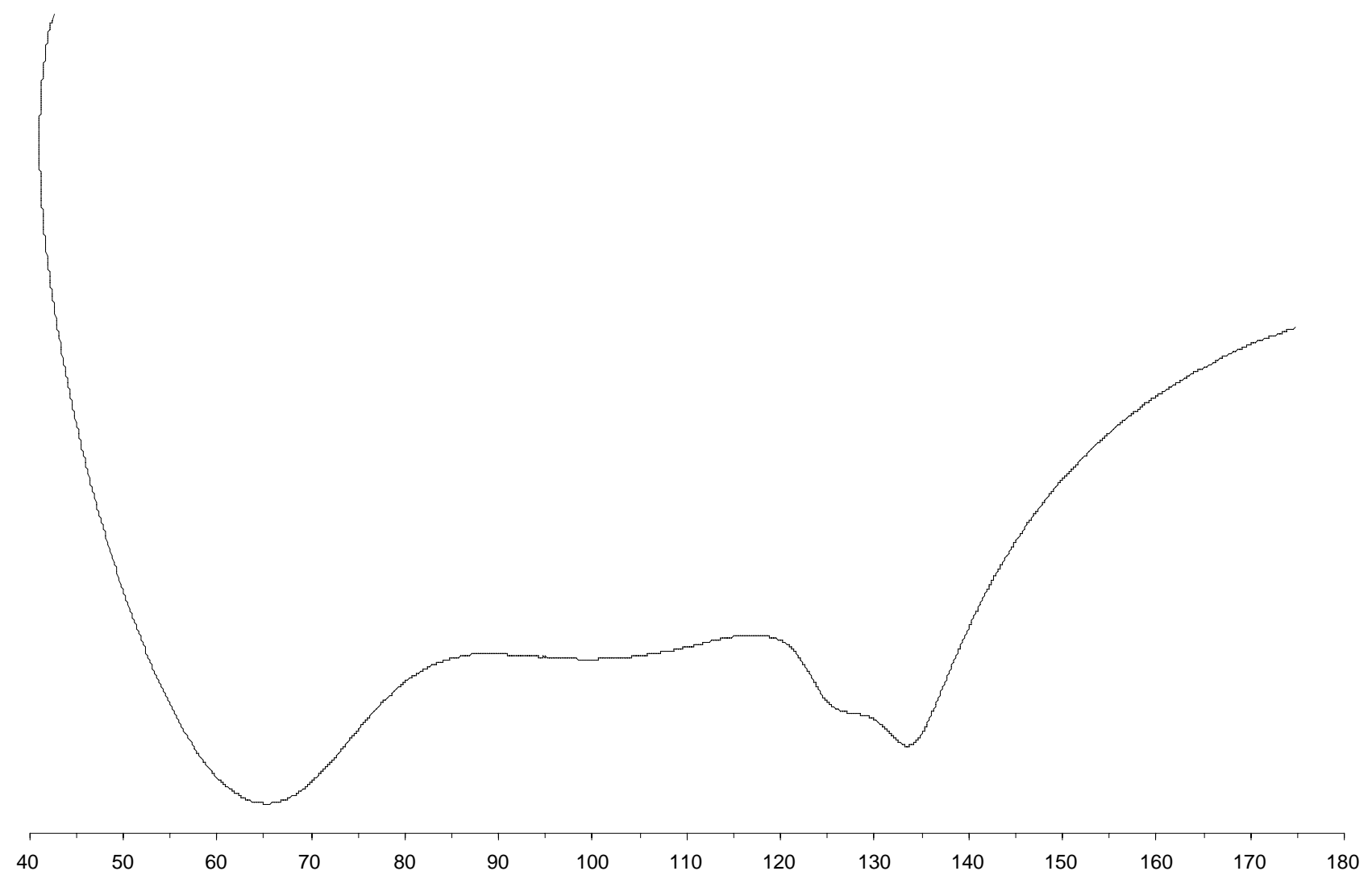


Copoly(propylene/1-octene) (1.4 mol \%) produced with 1/MAO (Table 1, entry 12 )

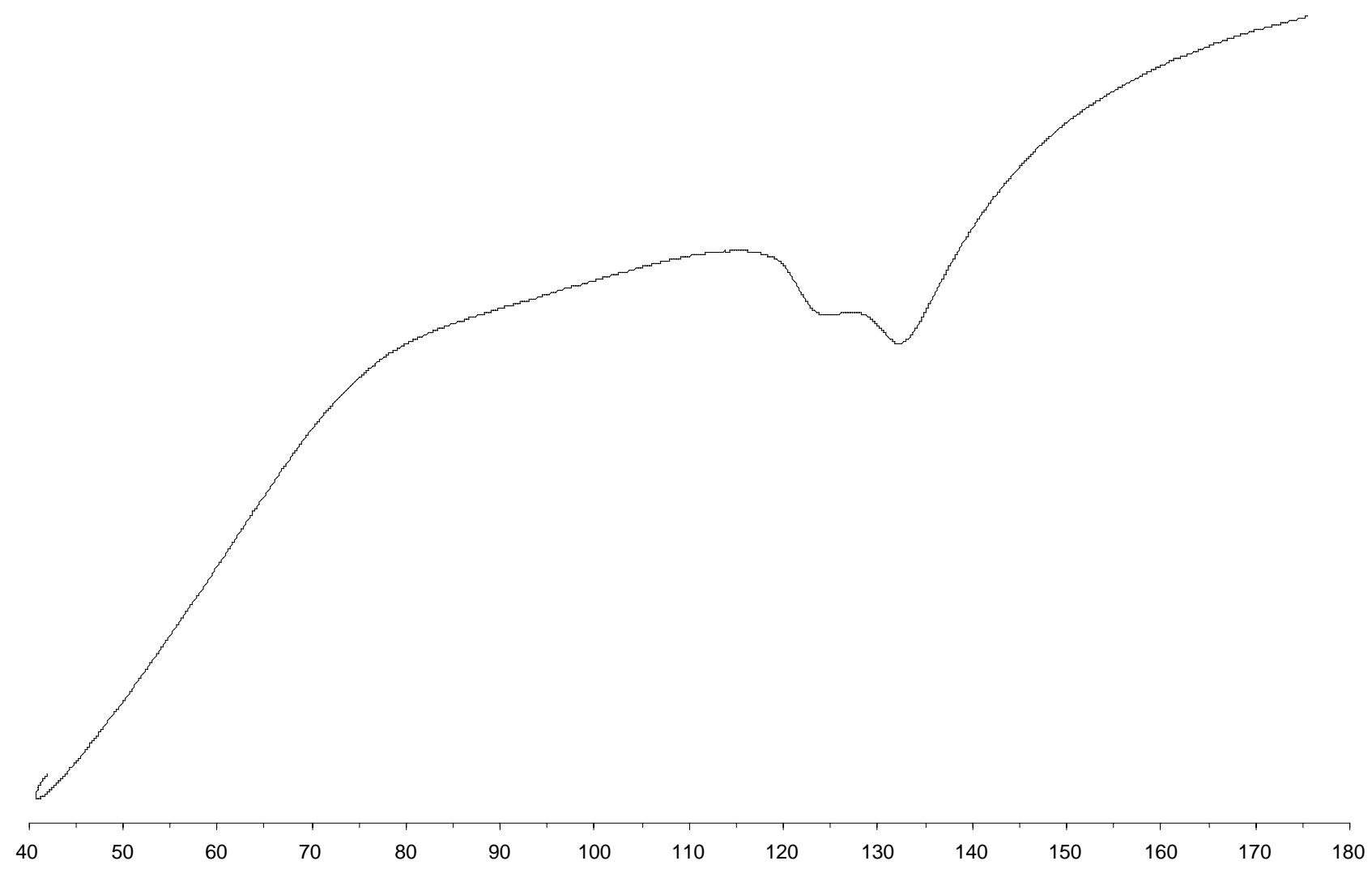


Copoly(propylene/1-decene) (1.2 mol \%) produced with 1/MAO (Table 1, entry 16)

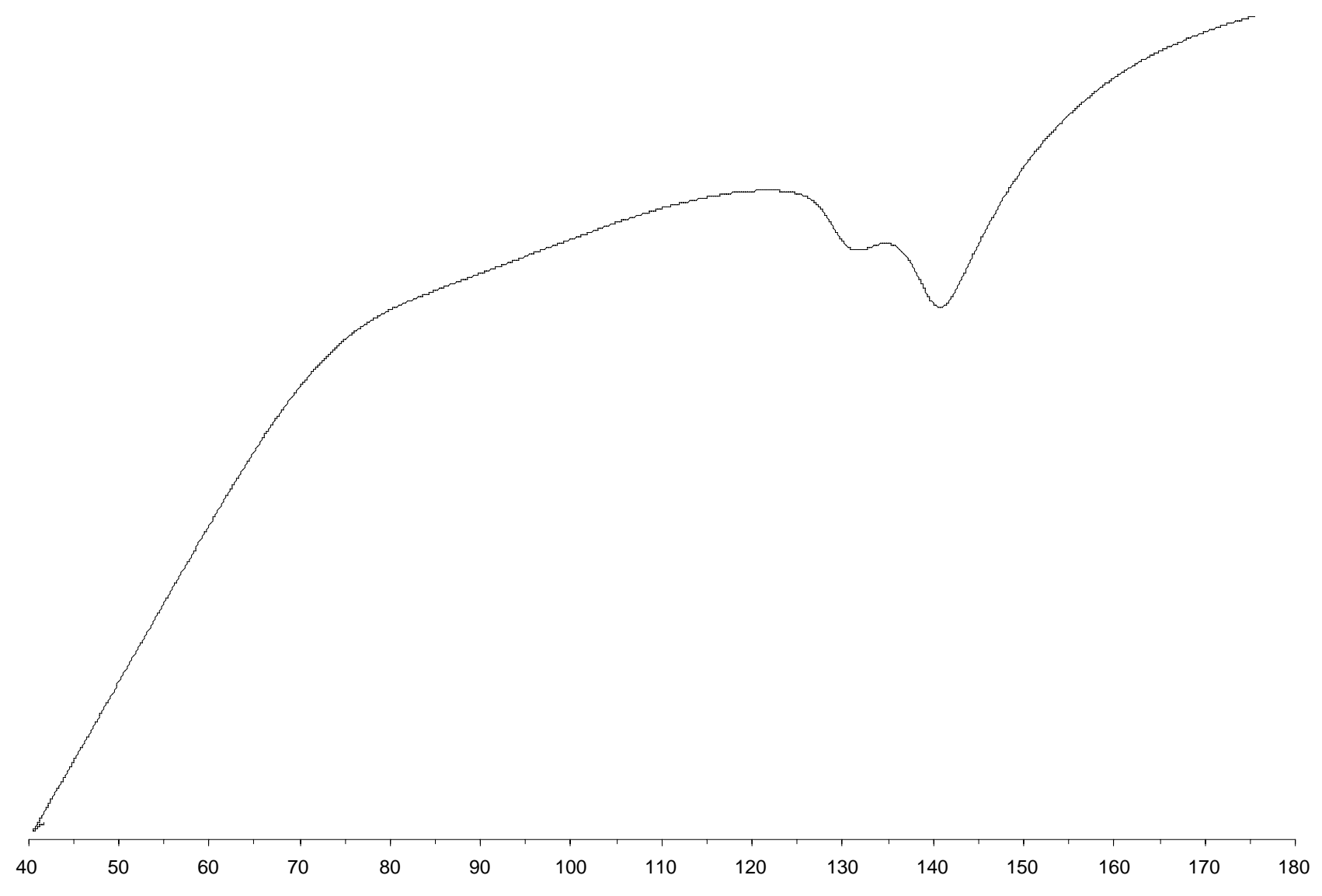


Copoly(propylene/4-methyl-1-pentene) (1.0 mol \%) produced with 2/MAO (Table 1, entry 20)

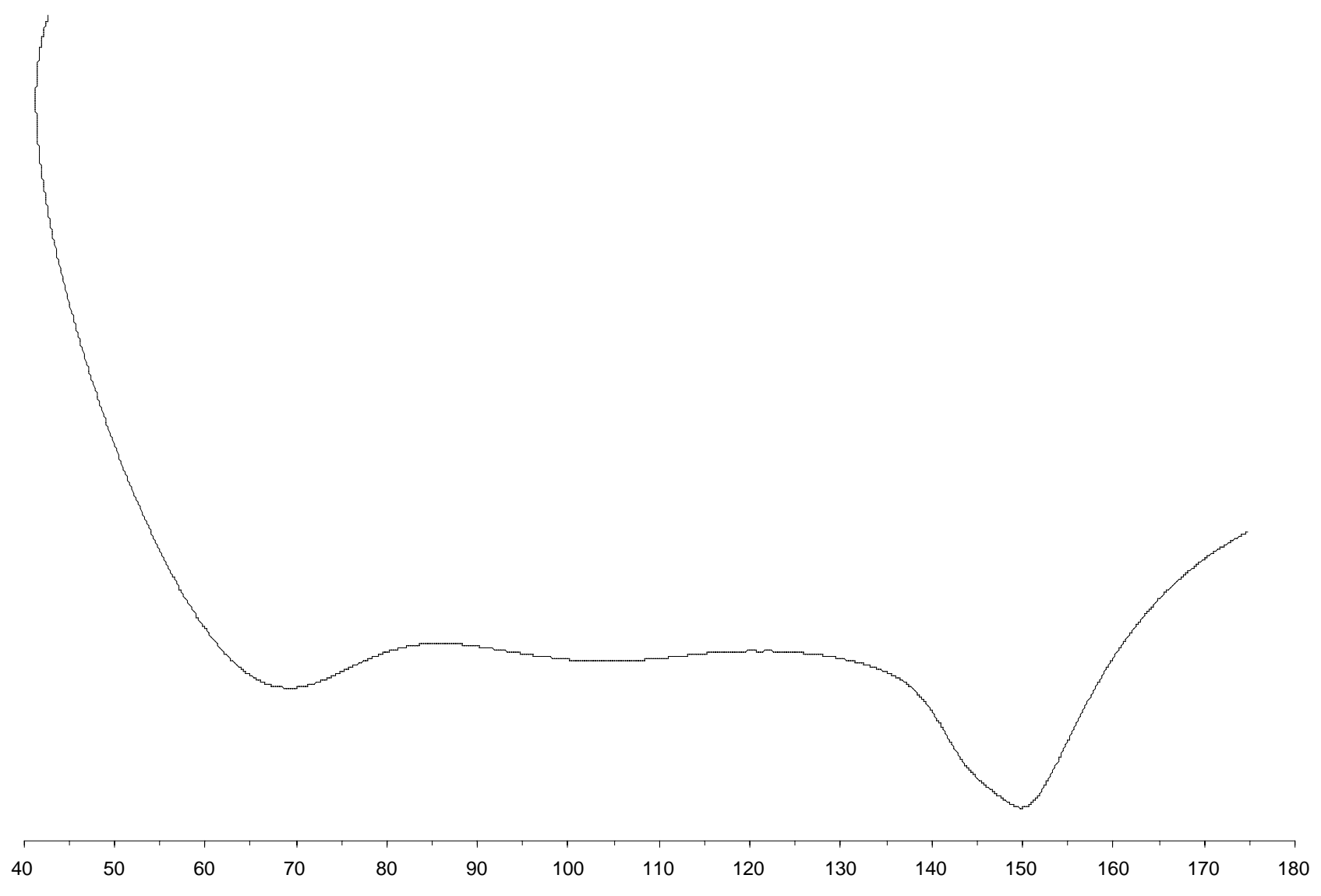


Copoly(propylene/1-hexene) (2.0 mol \%) produced with 2/MAO (Table 1, entry 24)

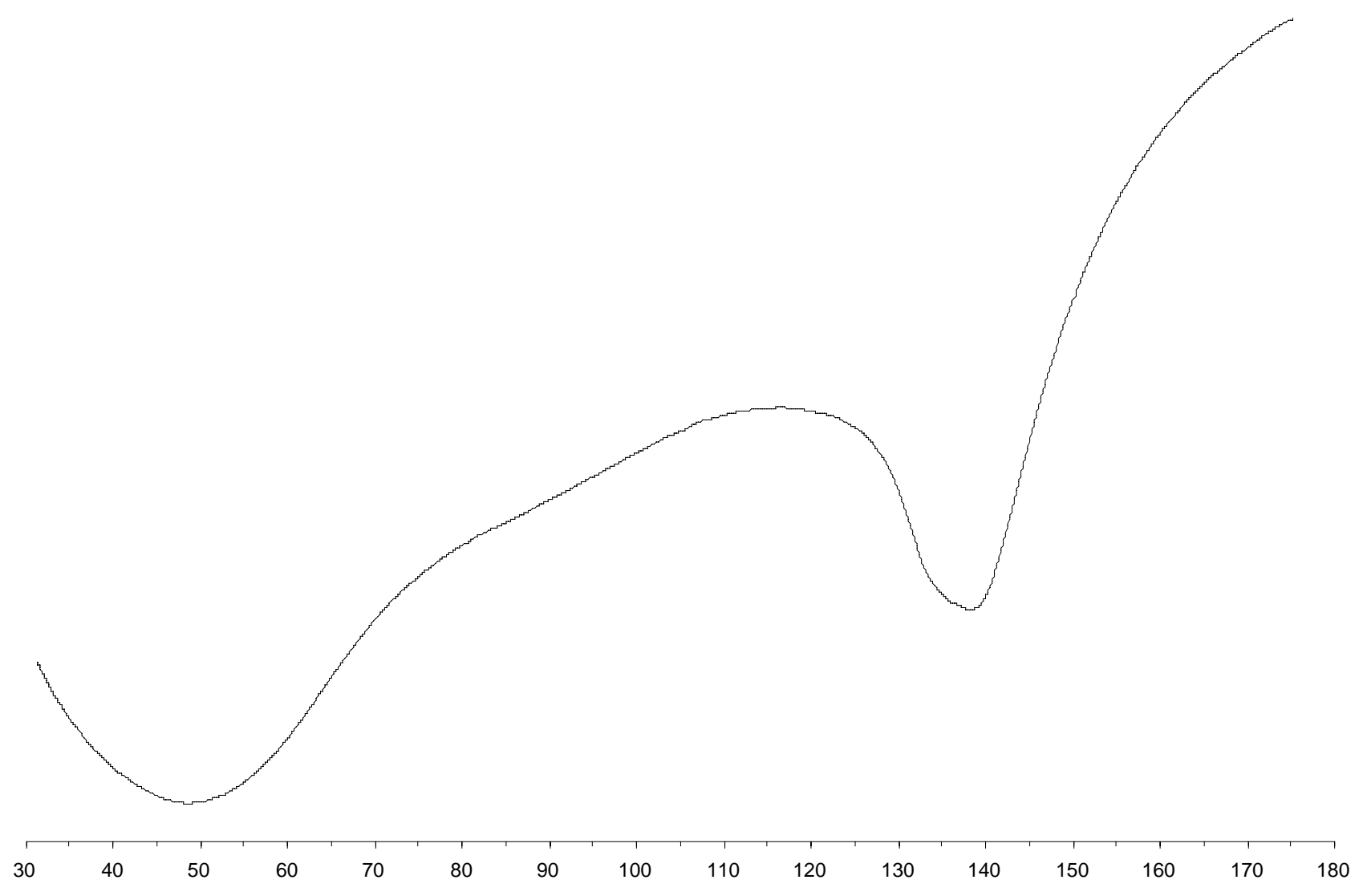


Copoly(propylene/1-octene) (0.9 mol \%) produced with 2/MAO (Table 1, entry 28 )

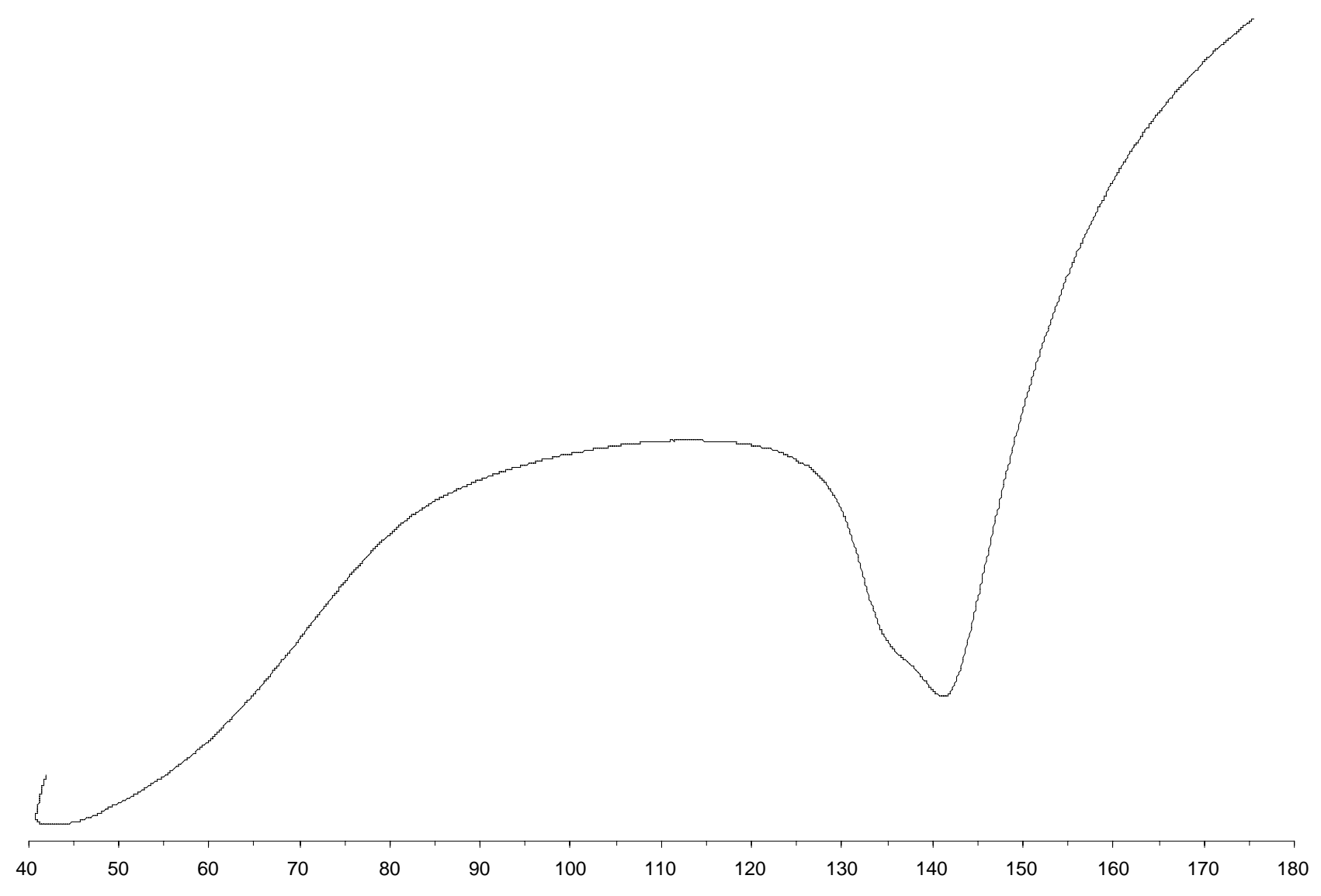


Copoly(propylene/1-decene) (0.9 mol \%) produced with 2/MAO (Table 1, entry 33)

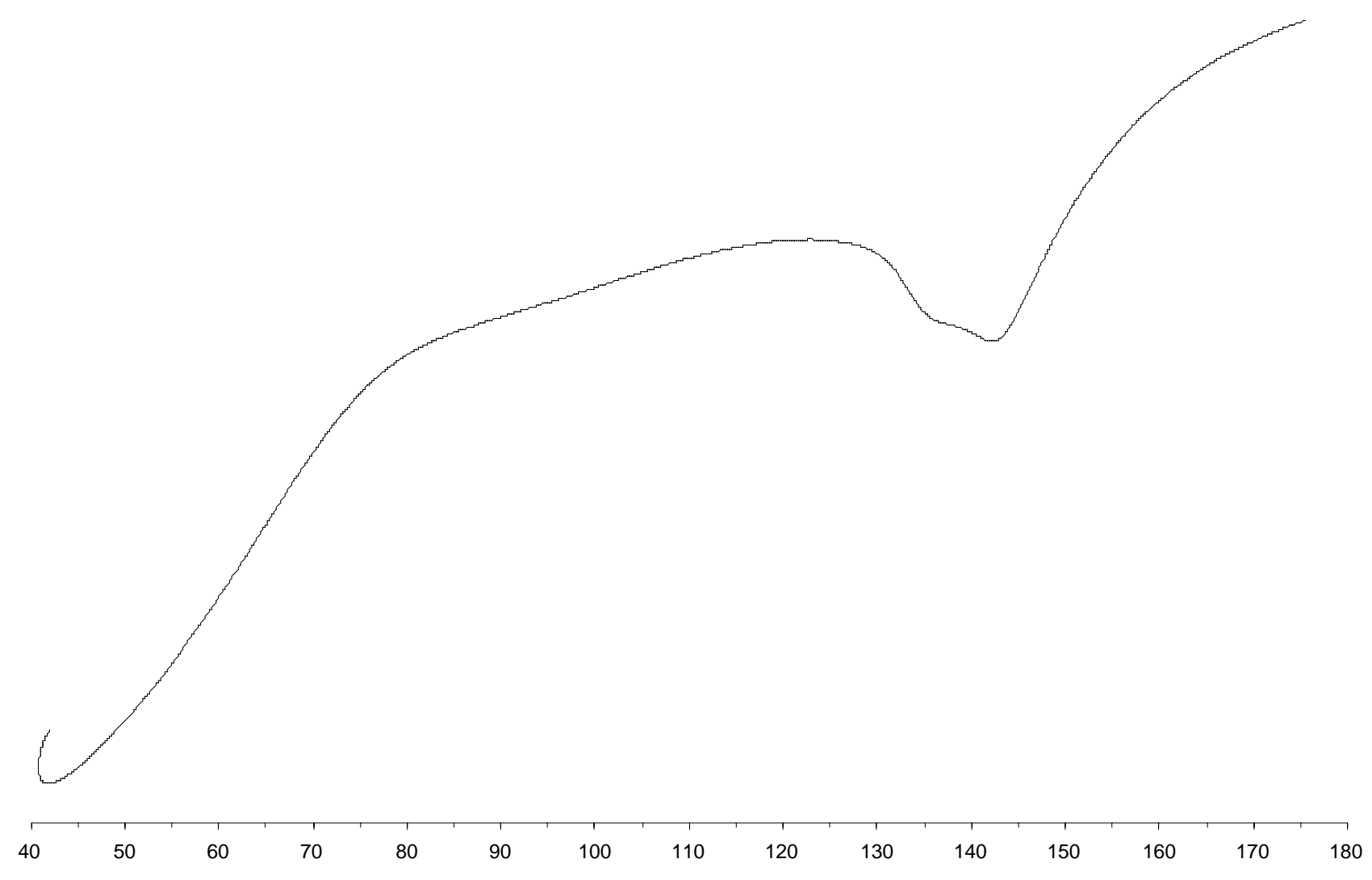


Copoly(propylene/4-methyl-1-pentene) (2.8 mol \%) produced with 3/MAO (Table 1, entry 38)

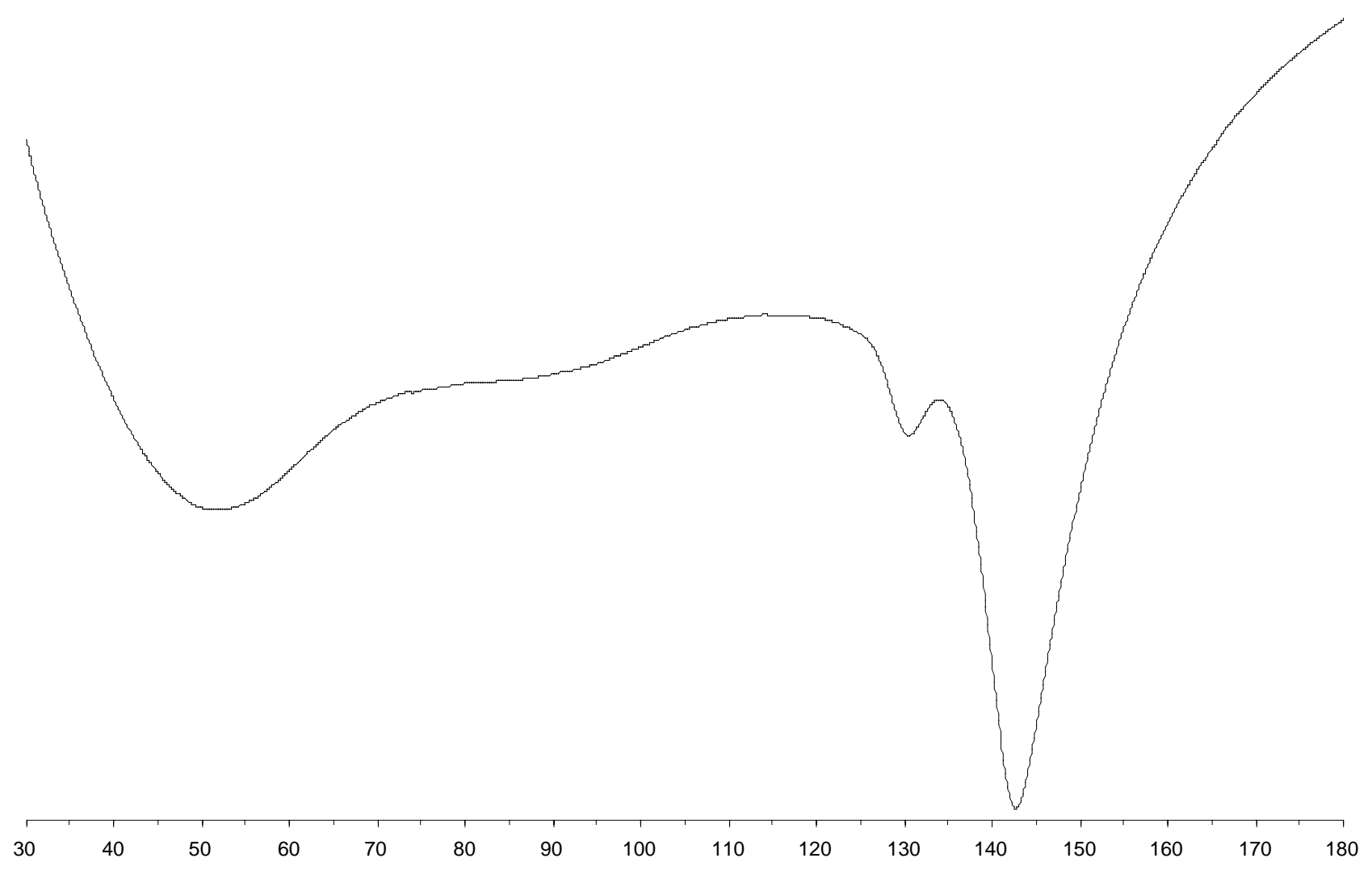


Copoly(propylene/1-hexene) (2.5 mol \%) produced with 3/MAO (Table 1, entry 42)

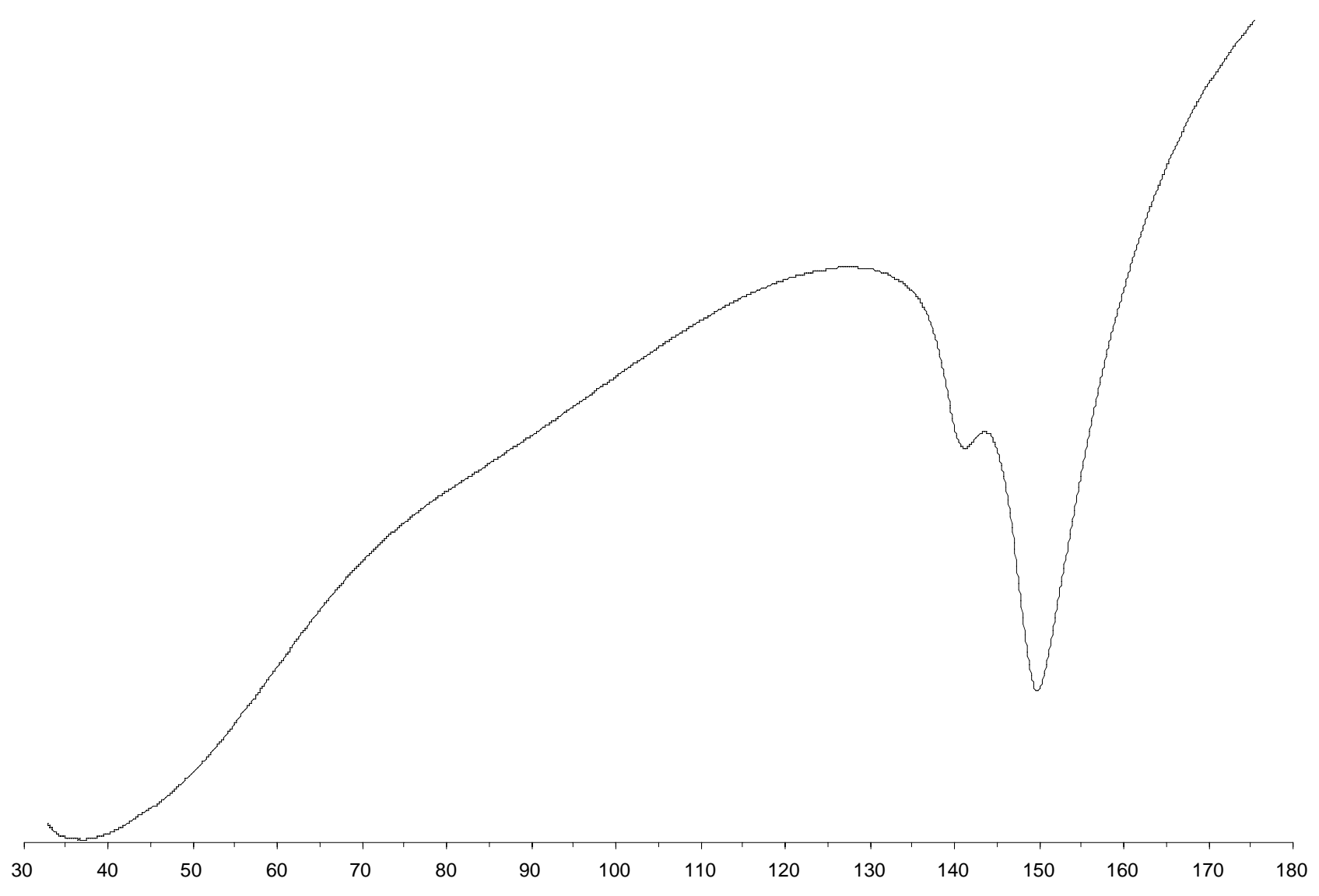


Copoly(propylene/1-octene) (1.0 mol \%) produced with 3/MAO (Table 1, entry 47)

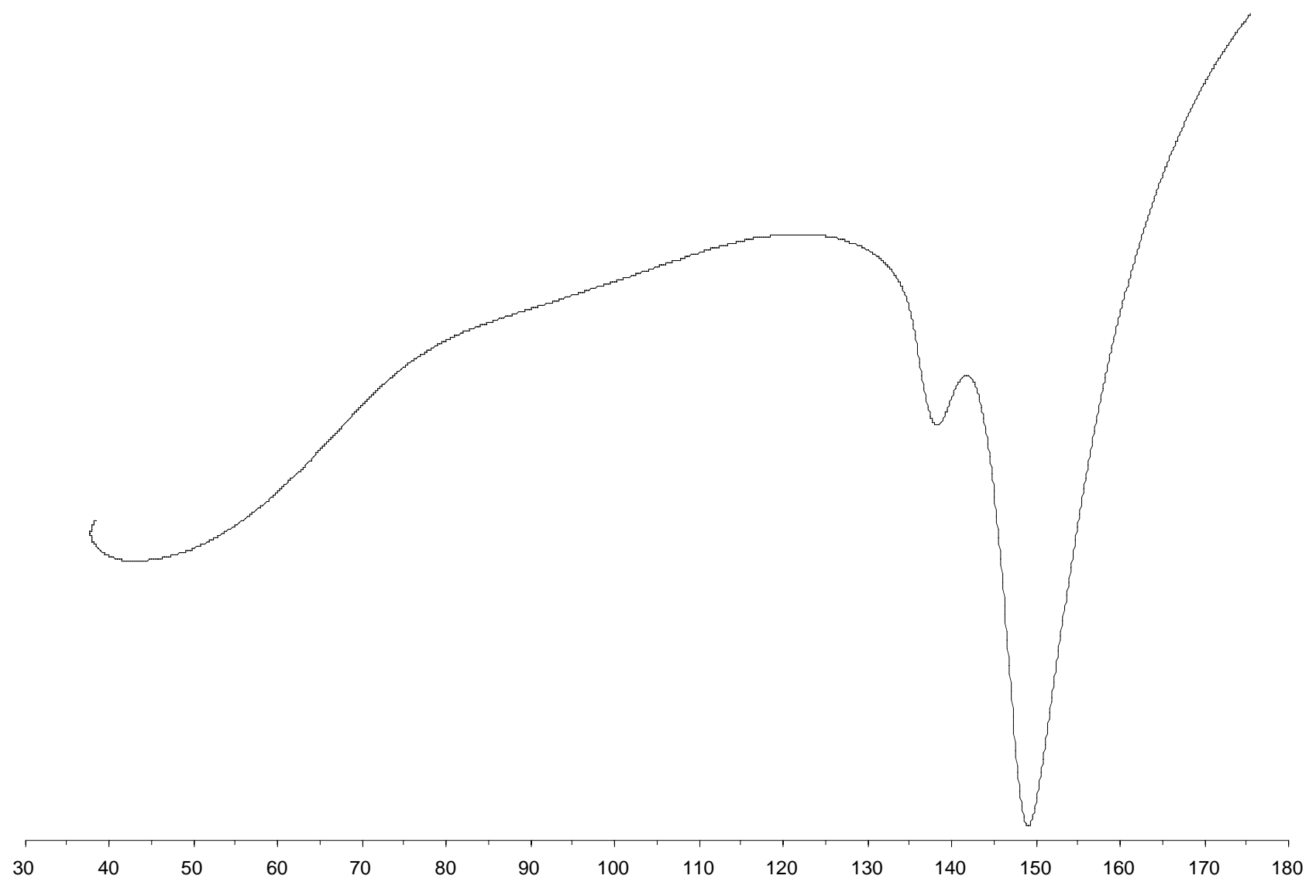


Copoly(propylene/1-decene) (1.2 mol \%) produced with 3/MAO (Table 1, entry 51)

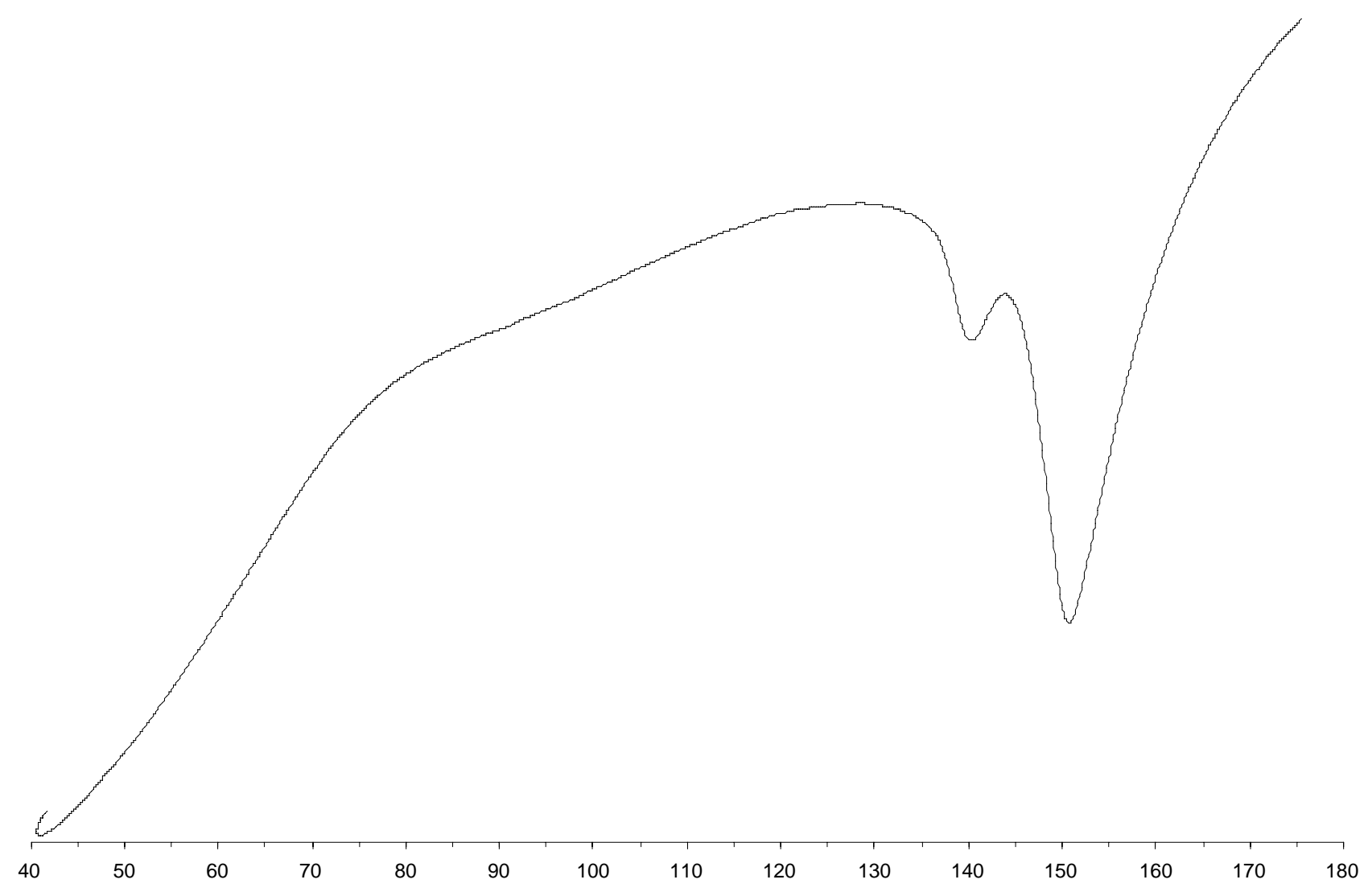




\section{Analysis of Monomer Sequence Distributions}

For a truly random copolymer of monomers $\mathbf{P}$ (propylene) and $\mathbf{C}$ (comonomer), one expects monomer dyad sequences to follow a statistical distribution. In particular, if we consider the incorporation $i$ of comonomer $\mathbf{C}$ (as a mole fraction, $0 \leq i \leq 1)$ in the copolymer, we expect the ratio of dyads PP : PC : CC to be $(1-i)^{2}: 2(1-i) i: i^{2}$. If the dyad sequences are diagnosed using the $\alpha \alpha$-methylene carbon peak in the ${ }^{13} \mathrm{C}$ NMR spectra, we can expect to only see PC and CC dyads when they constitute $\sim 1 \%$ or more of the total dyads. This means that for $i<0.08$, only PP and PC dyads will be observed; for greater incorporations, all three dyads may be observed and quantified. Comparing the ratios of the peak intensities to the expected statistical distributions, we find that the copolymers prepared in this study (using any of the three catalysts) closely follow the expected distributions, and are therefore "random" copolymers. For example, the copolymer from entry 46 provided a PP : PC : CC ratio of $62.38: 34.00: 3.63$ and a best-fit $i$ value of 0.212 . For $i=0.212$, the calculated ratio is $62.09: 33.41: 4.49$.

Since we have random copolymers, we can expect the monomer sequence tetrad or hexad distributions in these regions to again be statistical. In particular, in the PC dyad region, we expect the tetrads PPCP, PPCC, CPCP, and CPCC to show up in the ratio $(1-i)^{2}:(1-i) i: i(1-i): i^{2}$ and the hexads PPPCPP, PPPCPC, CPPCPP, РPРССР, РСРСРP, СРРСРС, РPРССС, СРРССР, РСРСРС, ССРСРР, РСРССР, СРРССС, ССРСРС, PCPCCC, CCPCCP, CCPCCC to appear in the ratio $(1-i)^{4}:(1-i)^{3} i:(1-i)^{3} i:(1-i)^{3} i:(1-i)^{3} i:(1-i)^{2} i^{2}:(1-i)^{2} i^{2}:(1-$ $i)^{2} i^{2}:(1-i)^{2} i^{2}:(1-i)^{2} i^{2}:(1-i)^{2} i^{2}:(1-i) i^{3}:(1-i) i^{3}:(1-i) i^{3}:(1-i) i^{3}: i^{4}$. For $i<0.01$, we expect only the PPCP peak to be significant, and for $0.01<i<0.10$, we expect only the first three tetrads to be quantifiable. Similarly, at the hexad level, we can expect either one, five, eleven, fifteen, or sixteen peaks to be quantifiable with cutoffs of $i \approx$ $0.01,0.11,0.23$, and 0.30 . Even at an incorporation of 0.05 , the expected tetrad distribution is approximately 90 : $5: 5: 0$ (one major and two relatively small peaks) and the expected hexad distribution is approximately 81.5 : $4.3: 4.3: 4.3: 4.3: 0: 0: 0: 0: 0: 0: 0: 0: 0: 0: 0$ (one major and four relatively small peaks). The experimental spectra of copolymers with less than five percent comonomer incorporation, however, show several peaks of comparable intensity in the PC dyad region. This indicates that a distribution other than monomer sequences is being observed.

If the branches have no effect on stereosequences, we should observe a stereochemical hexad distribution about the $\alpha \alpha$-methylene carbon in the $500 \mathrm{MHz}\left(125 \mathrm{MHz}{ }^{13} \mathrm{C}\right) \mathrm{NMR}$ spectrum of a polymer sample that corresponds to the pentad distribution observed about the propylene methyl peak in the $300 \mathrm{MHz}\left(75 \mathrm{MHz}{ }^{13} \mathrm{C}\right) \mathrm{NMR}$ spectrum. For any of the low-comonomer-incorporation samples considered in this work, this again corresponds to one major and two or three relatively small peaks. Even if we were to consider the interaction of monomer sequences and stereochemical sequences, we should still only observe one major and several (now even more so) minor peaks. However, the peaks observed in all such spectra are of comparable intensity. This indicates that the stereochemical environment near a branch on the polymer chain is significantly different from that at a distance from the branch.
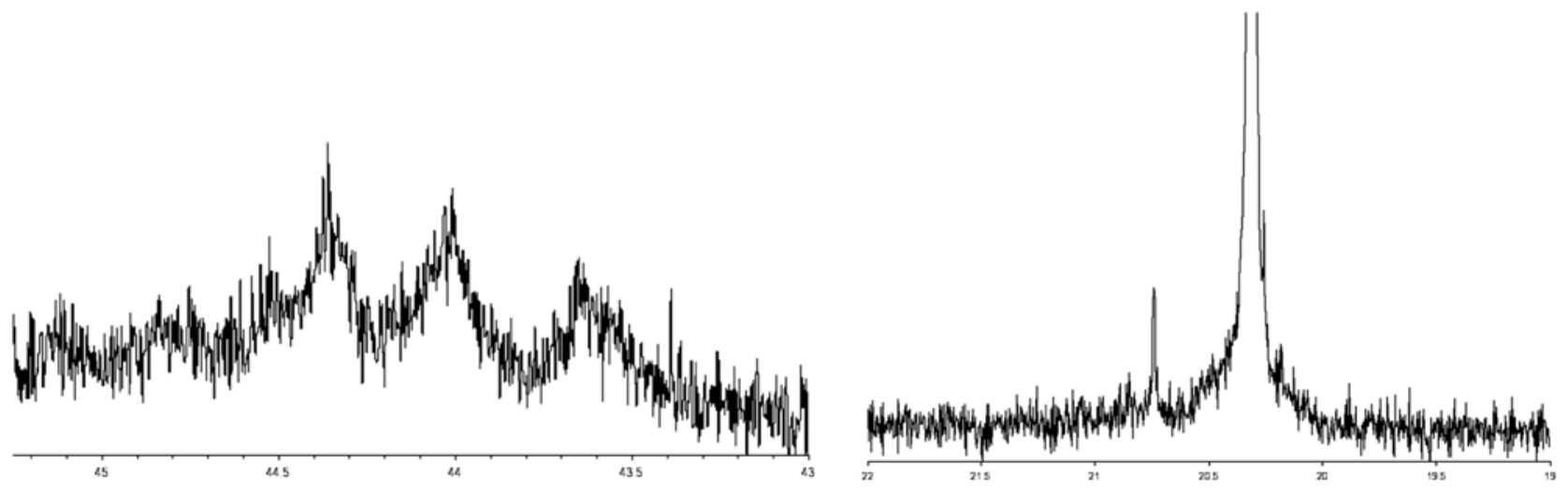

${ }^{13} \mathrm{C}$ NMR of the copolymer from Table 1, entry 24 (2.0\% 1-hexene). On the left is the PC dyad methylene region obtained using a $500 \mathrm{MHz}$ instrument $\left(125 \mathrm{MHz}{ }^{13} \mathrm{C}\right)$. On the right is the polypropylene methyl region obtained using a $300 \mathrm{MHz}$ instrument $\left(75 \mathrm{MHz}{ }^{13} \mathrm{C}\right)$.

\section{References}

(1) Irwin, L. J.; Miller, S. A. J. Am. Chem. Soc. 2005, 127, 9972-9973. 